\title{
The role of oligodendrocyte precursor cells expressing the GPR17 receptor in brain remodeling after stroke
}

\author{
Elisabetta Bonfanti ${ }^{1,5}$, Paolo Gelosa ${ }^{2,5}$, Marta Fumagalli ${ }^{1}$, Leda Dimou ${ }^{3}$, Francesca Viganò ${ }^{3}$, Elena Tremoli ${ }^{2}$, Mauro Cimino ${ }^{4,5}$, \\ Luigi Sironi $^{{ }^{*}, 1,2,5}$ and Maria P Abbracchio ${ }^{1,5}$
}

Following stroke-induced neuronal damage, quiescent oligodendrocyte precursors (OPCs) are activated to proliferate and later to differentiate to myelin-producing cells. GPR17, a receptor transiently expressed on early OPCs, has emerged as a target to implement stroke repair through stimulation of OPC maturation. However, being GPR17 completely downregulated in myelinproducing oligodendrocytes, its actual role in determining the final fate of OPCs after cerebral ischemia is still uncertain. Here, to univocally define the spatiotemporal changes and final fate of GPR17-expressing OPCs, we induced ischemia by middle cerebral artery occlusion (MCAO) in reporter GPR17iCreER ${ }^{\mathrm{T}}$ :CAG-eGreen florescent protein (GFP) mice, in which, upon tamoxifen treatment, cells expressing GPR17 become green and traceable for their entire life. Starting from 3 days and up to 2 weeks after $\mathrm{MCAo}, \mathrm{GFP}^{+}$cells markedly accumulated in regions surrounding the ischemic lesion; several of them proliferated, as shown by co-labeling of the DNA synthesis marker 5-Bromo-2'-deoxyuridine (BrdU). Almost all GFP ${ }^{+} / \mathrm{BrdU}^{+}$cells expressed the OPC early marker neural/glial antigen 2 (NG2), indicating that they were still precursors. Accumulation of GFP ${ }^{+}$cells was also because of OPC recruitment from surrounding areas, as suggested in vivo by acquisition of typical features of migrating OPCs, shown in vitro in presence of the chemoattractant PDGF-AA and confirmed by transplantation of GFP+-OPCs in wild-type MCAo mice. Eight weeks after MCAo, only some of these precociously recruited cells had undergone maturation as shown by NG2 loss and acquisition of mature myelinating markers like GSTpi. A pool of recruited GFP+-OPCs was kept at a precursor stage to likely make it available for further insults. Thus, very early after ischemia, GFP ${ }^{+}-O P C s$ proliferate and migrate toward the lesion; however, most of these cells remain undifferentiated, suggesting functional roles other than myelination.

Cell Death and Disease (2017) 8, e2871; doi:10.1038/cddis.2017.256; published online 8 June 2017

Neurological and neurodegenerative disorders are characterized by extensive loss of myelin sheath and defective remyelination. ${ }^{1}$ In the central nervous system (CNS), myelin is produced by oligodendrocytes, which originate from oligodendrocyte precursors (OPCs) expressing the neural/ glial antigen 2 (NG2). The proliferation and differentiation of OPCs are greatly increased after brain damage in the region adjacent to the ischemic 'core', when they contribute to remyelination. ${ }^{2}$ However, despite injury-induced OPC activation, damage also progresses at later phases after ischemia, indicating that the capability of OPCs to maturate to new myelinating oligodendrocytes is only partially successful. Interestingly, the presence of recruited immature OPCs is documented at the border of the lesion even at later times after injury, suggesting that either their differentiation is blocked at the pre-oligodendrocytes stage, or that these cells exert additional roles besides differentiation to myelinating cells.

Recent data have highlighted the GPR17 receptor as a potential target to implement repair and remyelination under neurodegenerative conditions. ${ }^{3-5}$ GPR 17 is already present in early $\mathrm{NG}^{+}$-OPCs, is induced in differentiating cells up to the immature oligodendroglial stage, and is then progressively downregulated to allow cells completing maturation.,
Interestingly, GPR17 expression is increased after traumatic brain injury in patients, ${ }^{8}$ after brain ischemia in mice ${ }^{4}$ and in several animal models of CNS injury. ${ }^{5,9-11}$ However, the process underlying the accumulation of GPR $17^{+}$cells at the site of ischemic lesions, ${ }^{4,12}$ the rate and kinetics of their maturation and their final fate are still largely unknown. Owing to the only transient expression of GPR17 that completely disappears before cells reach terminal maturation, it has been difficult to univocally follow in vivo the destiny and role of GPR17-expressing OPCs. To solve this problem, in this study we induced stroke by permanent middle cerebral artery occlusion (MCAo) in GPR17iCreER ${ }^{\mathrm{T} 2}$ :CAGeGreen florescent protein (GFP) transgenic mice, the first fluorescent reporter mouse line for GPR17 fate-mapping studies. In these mice, upon tamoxifen administration, enhanced GFP is expressed in OPCs where the GPR17 promoter is active, without affecting the physiological expression and function of the receptor. In this way, all cells expressing GPR17 at the time of tamoxifen administration (and their progeny) become fluorescent and can be easily visualized by fluorescence microscopy throughout their life. ${ }^{10}$

\footnotetext{
${ }^{1}$ Department of Pharmacological and Biomolecular Sciences, University of Milan, Milan, Italy; ${ }^{2}$ Centro Cardiologico Monzino, Milan, Italy; ${ }^{3}$ Physiological Genomics, Biomedical Center, Ludwig-Maximilians University, Munich, Germany and ${ }^{4}$ Department of Biomolecular Sciences, University of Urbino, Urbino, Italy

*Corresponding author: L Sironi, Department of Pharmacological and Biomolecular Sciences, University of Milan, Via Balzaretti 9, Milan 20133, Italy. Tel: +39 2 50318291; Fax: +39 2 50318250; E-mail: luigi.sironi@unimi.it

${ }^{5}$ These authors equally contributed to this work.

Received 11.1.17; revised 23.3.17; accepted 10.4.17; Edited by A Verkhratsky
} 
a
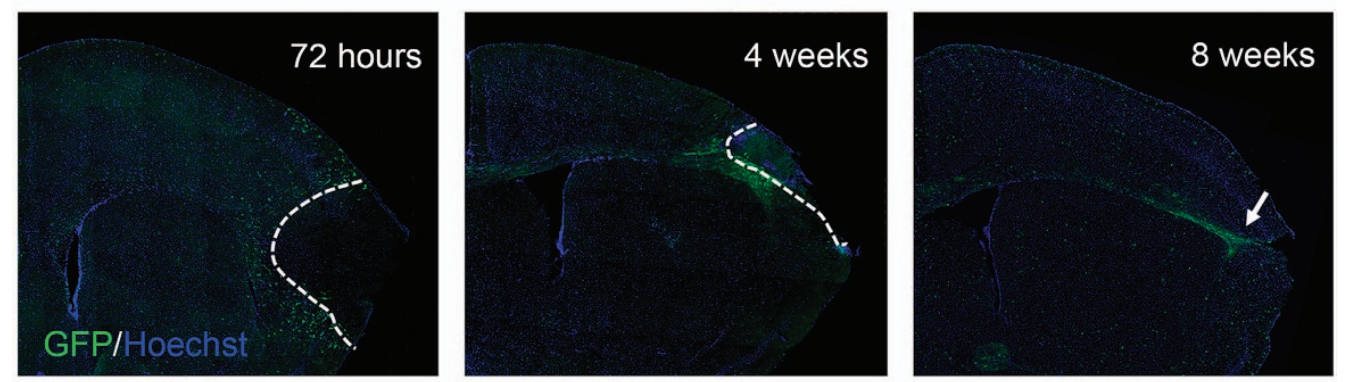

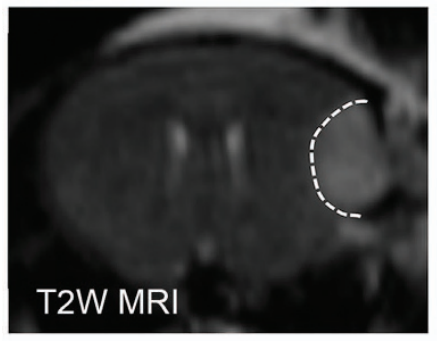

b

d
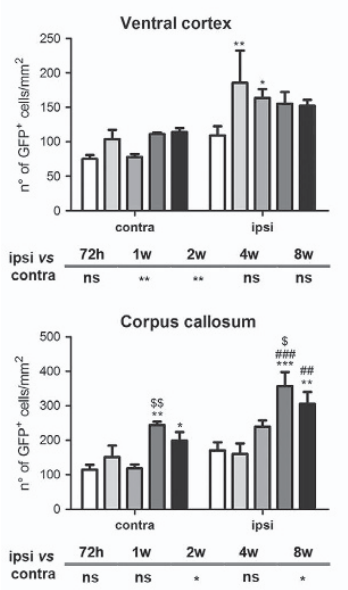
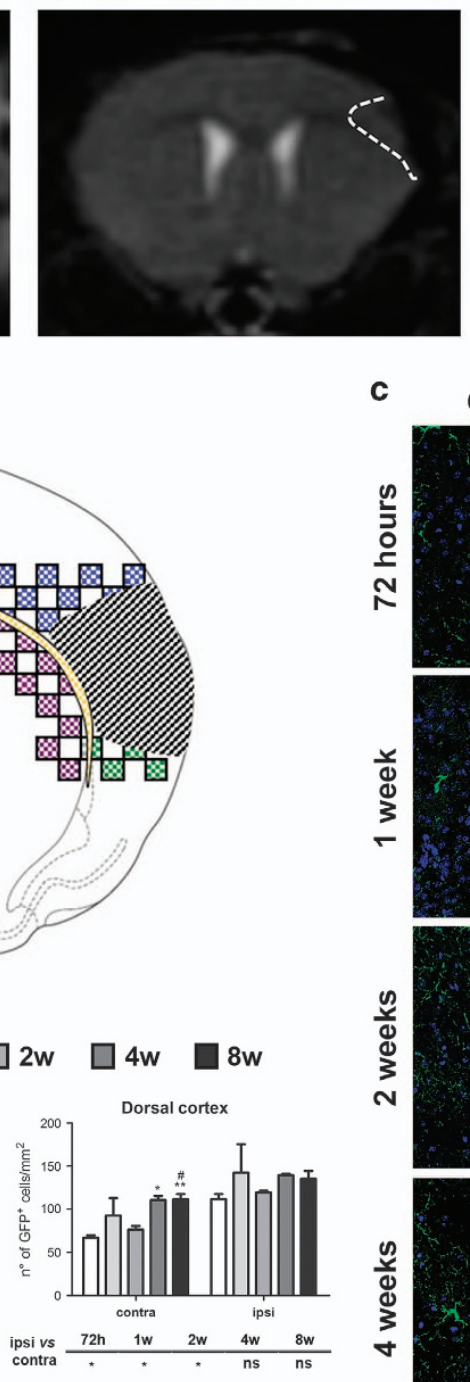

Striatum

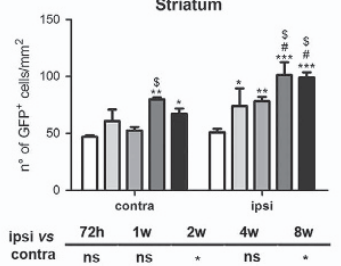

c
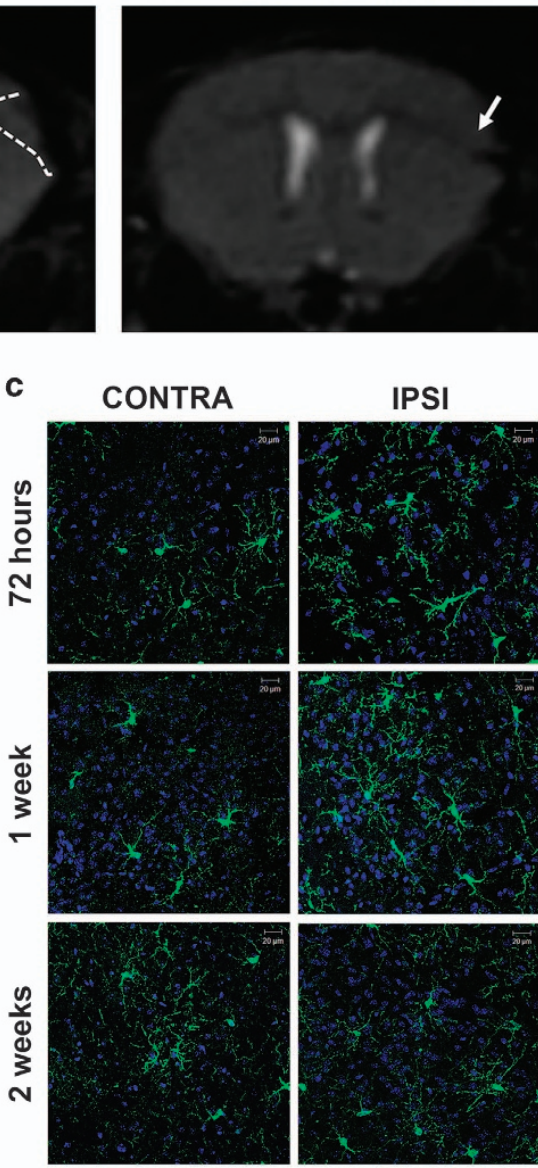

IPSI
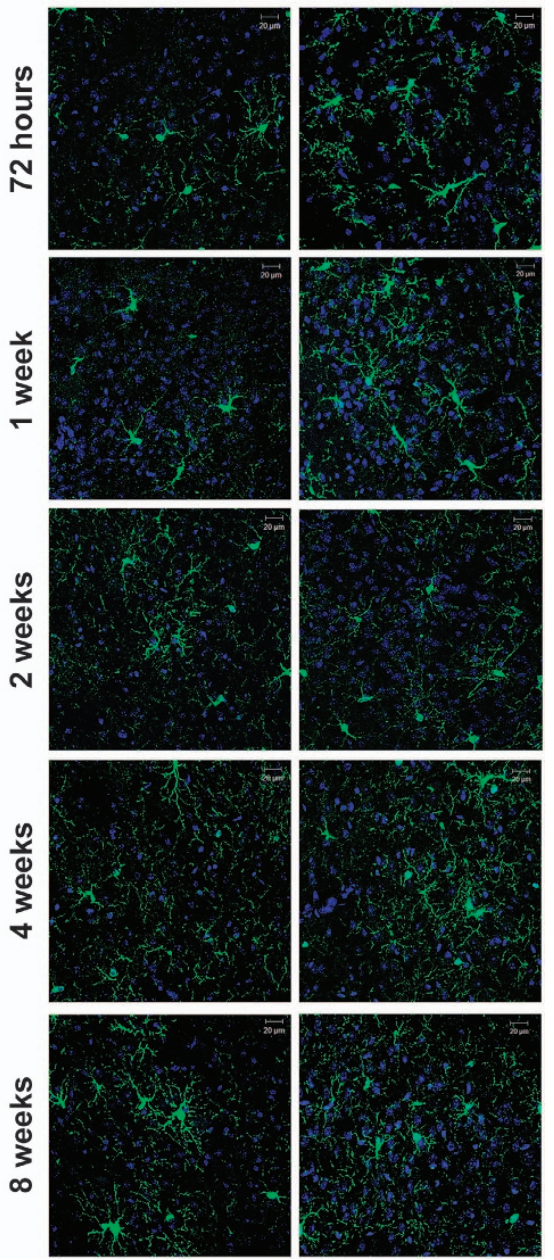


\section{Results}

After MCAo, GFP ${ }^{+}$-OPCs are rapidly recruited to the regions surrounding the ischemic lesion. Previous data on rodents indicate that, at early times after MCAo, GPR $17^{+}$OPCs start accumulating in the peri-lesion area, suggesting a role of these cells in reparative/regenerative processes. ${ }^{10,13}$ However, no data on the fate of these cells at longer times after MCAo are available. To shed light on this issue, we induced MCAo in the conditional GPR17iCreER ${ }^{\mathrm{T} 2}$ : CAG-eGFP mouse line for fate-mapping studies $^{10}$ (Supplementary Figure 1).

Figure 1a shows representative ipsilateral hemispheres $72 \mathrm{~h}$, and 4 and 8 weeks after MCAo, immunostained with an anti-GFP antibody. GFP ${ }^{+}$cells start accumulating early in the peri-infarcted area. With time, the ischemic area, as identified by MRI, became smaller and, 8 weeks after MCAo, GFP ${ }^{+}$cells delimited this area. To detail this ischemia-induced cell reaction, we analyzed four different regions of interest (ROls: dorsal cortex, ventral cortex, corpus callosum and striatum) (Figure 1b). Two-way ANOVA analysis demonstrates that both the ischemia and time factors significantly affected the number of $\mathrm{GFP}^{+}$cells, but there was no interaction between these two parameters. Regarding the ischemia factor, at early time points (i.e., within 2 weeks) a significant increase in the number of $\mathrm{GFP}^{+}$cells was observed in ventral and dorsal cortex of the ipsilateral compared with the contralateral side. At later time points (i.e., starting from 2 weeks), a significant increase in the number of GFP $^{+}$cells was observed only in corpus callosum and striatum. These different behaviors suggest a gradient in the detected changes, which develop with a slower kinetic in ROls more distal from damage (Figures 1c and d). In sham-operated animals, no differences in the number of $\mathrm{GFP}^{+}$cells in the ipsilateral compared with contralateral sides were found (data not shown). We conclude that the higher numbers of $\mathrm{GFP}^{+}$cells in the ipsilateral side of MCAo mice are specifically related to induction of brain ischemia.

Regarding the time factor, an increase in $\mathrm{GFP}^{+}$cells was observed 'per se' in the contralateral uninjured sides of all analyzed ROIs (Figures 1c and d), suggesting that the number of cells increases with age. In the ischemic sides at later times after MCAo, the number of $\mathrm{GFP}^{+}$cells was significantly increased compared with $72 \mathrm{~h}$ only in corpus callosum and striatum (see legend of Figure 1d), suggesting different kinetics in the development of ischemic consequences in the different ROls.

To further investigate these differences, we then performed a Pearson and simple linear regression analysis (Figure 2). Data confirmed a positive correlation between the number of $\mathrm{GFP}^{+}$cells and time from surgery in all contralateral uninjured ROIs, whereas in the ipsilateral ischemic sides this correlation was present only for striatum and corpus callosum (Supplementary Table 1). The lack of a linear correlation with time for ventral and dorsal cortex suggests that, in regions closer to damage, tissue remodeling is more complex and cannot be simply described by a linear equation. Data also suggest that, in these ROls, changes are likely to have already occurred by $72 \mathrm{~h}$.

After MCAo, GFP ${ }^{+}-$OPCs are rapidly polarized toward the lesion and then undergo morphological changes. Close to ischemic damage, OPCs have been reported to assume
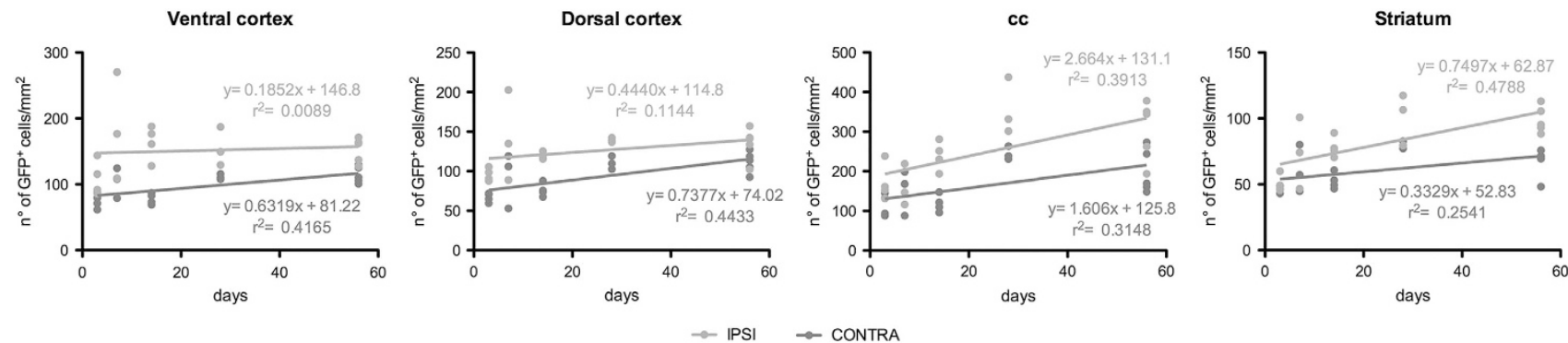

Figure 2 Correlation between the increase of $\mathrm{GFP}^{+}$cells and days from the MCAo in the contralateral and ipsilateral ROls. Scatter plot representation of the positive correlation between days from MCAO ( $x$ axis) and number of $\mathrm{GFP}^{+}$cells ( $y$ axis) in different ROls

Figure $1 \mathrm{GFP}^{+}$cells are recruited in regions surrounding the ischemic lesion. (a) Representative image of GFP immunofluorescence in ischemic brain slices from GPR17iCreER ${ }^{T 2}$ :CAG-eGFP mice $72 \mathrm{~h}, 4$ and 8 weeks after MCAo. Representative T2W brain images of the same mouse at the same slice level for each time point. At $72 \mathrm{~h}$, the dashed line delimitates the vasogenic edema, which is not visible at 4 weeks after MCAo (the dashed line delimitates the atrophic damage). Arrow indicates the elongation of corpus callosum and the cortical atrophy at 8 weeks after MCAo. (b) Drawing showing the ischemic lesion (dashed area) and the sampled fields in the selected ROls: dorsal cortex (blue), ventral cortex (green), corpus callosum, cc (yellow) and corpus striatum (purple). (c) Representative images of GFP ${ }^{+}$cells (green) and HOECHST 33258 (blue) in contralateral and ipsilateral dorsal cortex over time. Scale bar $=20 \mu \mathrm{m}$. (d) Bar graphs of the quantitative analysis of the number of GFP' cells in the selected ROls of both hemispheres ( $n=3$ mice for 1 week and 4 weeks; $n=4$ mice for $72 \mathrm{~h}$ and 2 weeks; $n=5$ mice for 8 weeks). Two-way ANOVA analysis demonstrates that both the ischemia $(P<0.001)$ and time $\left(P<0.05\right.$ for ventral cortex, $P<0.01$ for dorsal cortex and $P<0.001$ for corpus callosum and striatum) significantly affected the number of GFP ${ }^{+}$cells. The effect of ischemia is reported in the small tables below each graph: ${ }^{*} P<0.05,{ }^{\star \star} P<0.01$, ipsilateral versus contralateral side; Bonferroni post-hoc analysis. The effect of time is reported on each graph: ${ }^{*} P<0.05,{ }^{\star \star} P<0.01,{ }^{* \star \star} P<0.001$ versus $72 \mathrm{~h} ;{ }^{\#} P<0.05$, ${ }^{\# \#} P<0.01,{ }^{\# \#} P<0.001$ versus 1 week; ${ }^{\$} P<0.05,{ }^{\$ \$} P<0.01$, versus 2 weeks; Bonferroni post-hoc analysis 
monopolar/bipolar shape with elongated processes, ${ }^{14}$ which have been interpreted as a prerequisite for their migration. ${ }^{15}$ To investigate whether MCAo modifies the morphology of
GFP $^{+}$cells, we performed a Sholl and Skeleton analysis in dorsal cortex regions at $72 \mathrm{~h}, 1$ and 2 weeks after MCAo (Figures 3c-e).

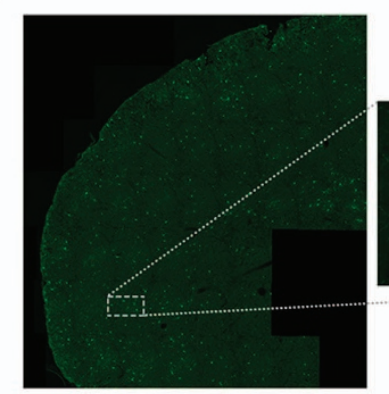

C

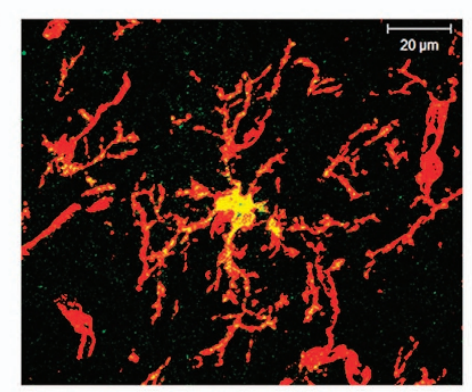

f

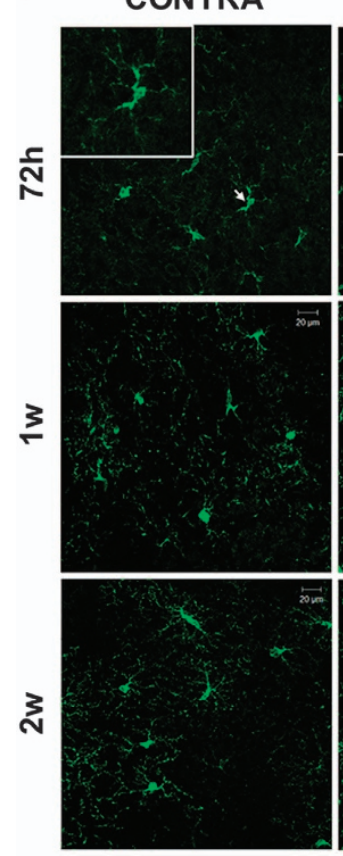

i

i d

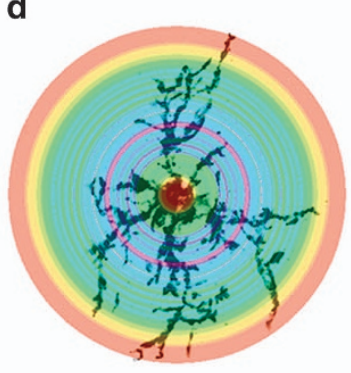

g
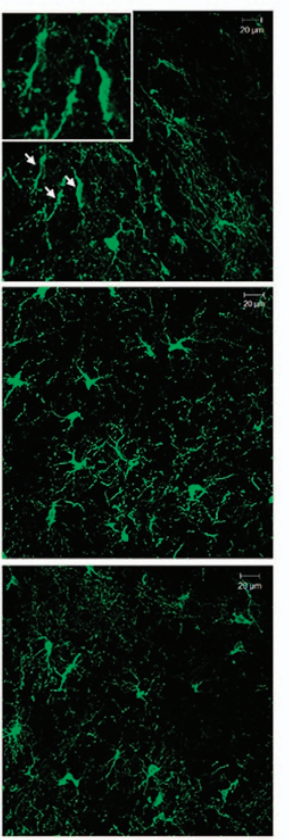

b

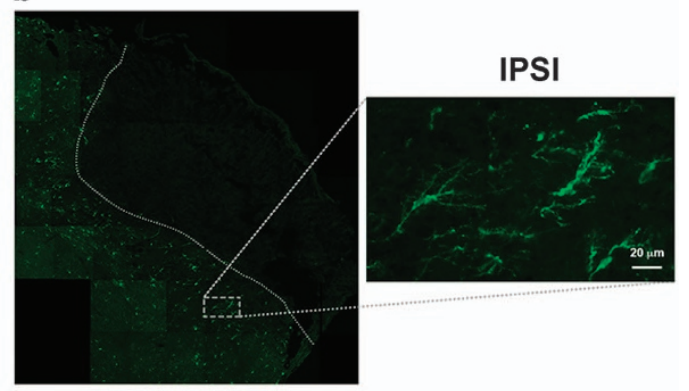

e

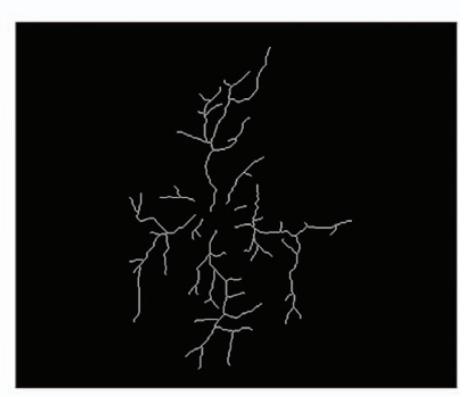

h
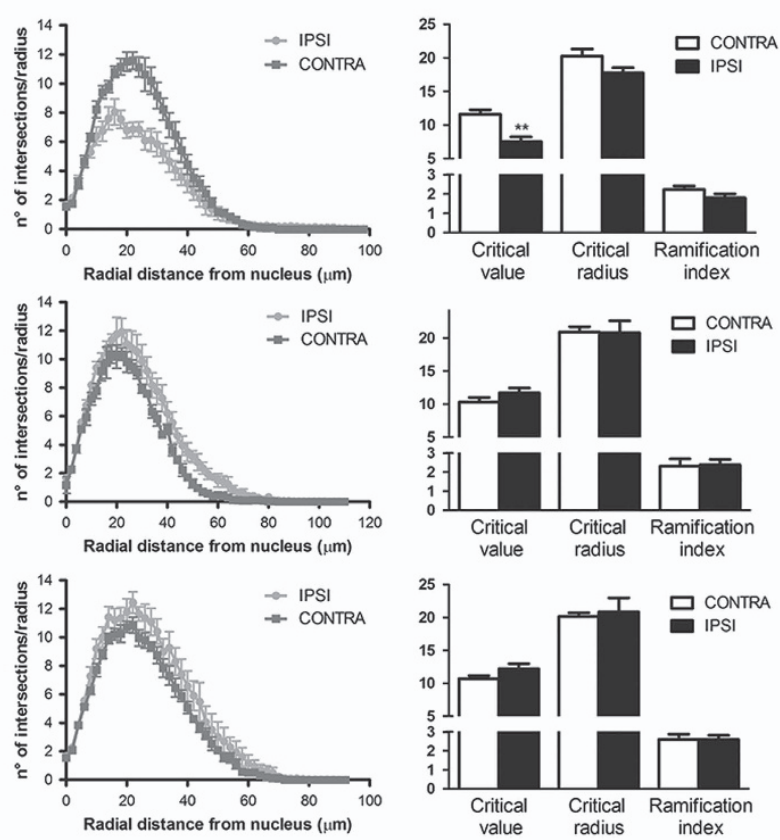

Skeleton analysis summary

\begin{tabular}{cccccc}
\multicolumn{2}{c}{$72 \mathrm{~h}$} & \multicolumn{2}{c}{$1 \mathrm{w}$} & \multicolumn{2}{c}{$2 \mathrm{w}$} \\
\hline \hline ipsi & contra & ipsi & contra & ipsi & contra \\
$11.24 \pm 1.07\left(^{* *}\right)$ & $15.09 \pm 0.64$ & $21.94 \pm 1.59$ & $19.63 \pm 2.85$ & $20.55 \pm 1.29$ & $17.76 \pm 0.85$ \\
$4.95 \pm 0.51\left(^{* *}\right)$ & $6.85 \pm 0.31$ & $10.62 \pm 0.79$ & $9.02 \pm 1.38$ & $9.63 \pm 0.64$ & $8.17 \pm 0.40$ \\
$7.01 \pm 0.52\left(^{*}\right)$ & $8.91 \pm 0.31$ & $12.30 \pm 0.78$ & $10.92 \pm 1.29$ & $11.74 \pm 0.64$ & $10.20 \pm 0.40$ \\
$10.83 \pm 0.58\left(^{* *}\right)$ & $7.43 \pm 0.24$ & $6.67 \pm 0.23$ & $7.15 \pm 0.29$ & $6.84 \pm 0.23(*)$ & $7.69 \pm 0.25$ \\
$18.64 \pm 0.76\left(^{*}\right)$ & $16.37 \pm 0.44$ & $17.33 \pm 0.76$ & $16.64 \pm 0.70$ & $17.02 \pm 0.57$ & $16.84 \pm 0.50$ \\
$61.53 \pm 1.95$ & $59.20 \pm 1.18$ & $62.73 \pm 2.07\left(^{* * *}\right)$ & $51.25 \pm 1.32$ & $57.66 \pm 1.37$ & $59.48 \pm 1.60$ \\
83 & 78 & 53 & 56 & 72 & 72
\end{tabular}


At $72 \mathrm{~h}$, in ipsilateral side, $\mathrm{GFP}^{+}$cells showed a simpler morphology with fewer and more elongated processes polarized to the lesion, to suggest that these cells are attracted to the damaged area (Figures $3 b$ and f). Indeed, ischemia induced an early change of the Sholl plot profile, a reduction of the critical value, a decrease of the number of branches, process endpoints and junctions, and an increase of branch length parameters (Figures $3 g-i)$. On the contrary, 1 and 2 weeks, morphological parameters did not show any significant difference, suggesting that the morphological changes of $\mathrm{GFP}^{+}$cells mainly occur at early times (Figures $\left.3 g-i\right)$.

To investigate whether the morphology of $\mathrm{GFP}^{+}$cells was influenced by ischemia-induced maturation of OPCs, we analyzed separately the $\mathrm{GFP}^{+} / \mathrm{NG}^{+}$and $\mathrm{GFP}^{+} / \mathrm{NG}^{-}$cells (representing, respectively, early or more mature OPCs). We found that the morphological changes observed in $\mathrm{GFP}^{+}$cells in ipsilateral side at $72 \mathrm{~h}$, were restricted to the $\mathrm{GFP}^{+} / \mathrm{NG}^{+}$ cellular sub-population. A detail description of the results is reported in Supplementary Figure 2.

Globally, these results indicate that ischemia induces phenotype-and time-dependent changes in the morphological structure of $\mathrm{GFP}^{+}$cells.

The migratory capacity of GFP $^{+}$-OPCs is markedly increased after MCAo. To assess whether the ischemiainduced morphological changes of $\mathrm{GFP}^{+}$-OPCs are indeed associated with altered migratory abilities, we performed an in vitro cell migration assay. For these experiments, we used OPCs isolated from neonatal GPR17iCreER ${ }^{\mathrm{T} 2}$ :CAG-eGFP fluorescent mice containing both $\mathrm{GFP}^{+}$and $\mathrm{GFP}^{-}$cells. The vast majority of these $\mathrm{GFP}^{+}$and $\mathrm{GFP}^{-}$cells expressed both NG2 $(90.89 \pm 4.48 \%$ and $83.86 \pm 5.29 \%$, respectively; Figure $4 \mathrm{a})$ and GPR17 $(91.28 \pm 8.67 \%$ and $76.85 \pm 8.71 \%$, respectively; Figure $4 \mathrm{~b})$. In the presence of PDGF-AA, a known chemoattractant factor accumulating at ischemic lesions, both $\mathrm{GFP}^{+}$and $\mathrm{GFP}^{-}$-OPCs showed significantly increased motility $(33.42 \pm 7.09 \%$ and $51.0 \pm 8.67 \%$, respectively) compared with unstimulated cells (Figure 4c), to confirm that, in a similar way to normal OPCs, recombinant $\mathrm{GFP}^{+}$-OPCs are sensitive to chemoattractant signals. ${ }^{16}$

To evaluate whether the presence of NG2 modifies GFP ${ }^{+}$ cell migratory capacity, we better characterized the $\mathrm{GFP}^{+}$ migrated cell population. No differences in the percentage of $\mathrm{NG}^{+}$cells within $\mathrm{GFP}^{+}$migrated cells were found either in the presence or in the absence of PDGF-AA. Moreover, we observed no significant changes in the percentage of $\mathrm{NG}^{+}$ and NG2 ${ }^{-}$cells in the $\mathrm{GFP}^{+}$cell populations before (Figure 4a) and after (Figure 4d) migration. Taken together, these data suggest that the presence of NG2 does not confer additional migratory capacities to the specific subcellular population of OPCs expressing GPR17 (Figure 4d).

To detail the migratory abilities of OPCs in vivo after MCAo, we transplanted fluorescent $\mathrm{GFP}^{+}$-OPCs in wild-type mice (Figure $4 \mathrm{e}$ ). At the time of the graft, almost all fluorescent transplanted cells did express GPR17 (Figure 4b and above). One week after the graft, many GFP $^{+}$-OPCs had moved away from the site of injection of a distance up to $900 \mu \mathrm{m}$ in MCAo mice showing greater migratory abilities compared with shamoperated mice (Figure 4f).

Then, to investigate whether the presence of GPR17 confers different abilities to the transplanted cells, we quantified the percentage of $\mathrm{GFP}^{+}$cells expressing or not expressing GPR17 1 week after the injection. In shamoperated mice, the percentage of all the transplanted GFP ${ }^{+}$ cells that still maintained GPR17 was significantly lower (about $30 \%)$ compared with the cells that had lost the receptor (Figure $4 \mathrm{~g}$ ), suggesting progression to more differentiated stages. Instead, in MCAo mice, the percentage of cells maintaining GPR17 was about the $50 \%$ of total GFP $^{+}$cells (Figure 4g).

Altogether, these data demonstrate that the ischemic environment modifies the mobility of $\mathrm{GFP}^{+}-\mathrm{OPCs}$, recruiting them from the parenchyma to the areas surrounding the lesion and likely inducing the release of factors maintaining GPR17 expression and thus preserving $\mathrm{GFP}^{+}$cells at a precursor stage. We also speculate that the presence of GPR17 favors OPC migration, as shown by the increased number of GPR $17^{+}$ cells at greater distances from the injection side in MCAo compared with sham-operated mice.

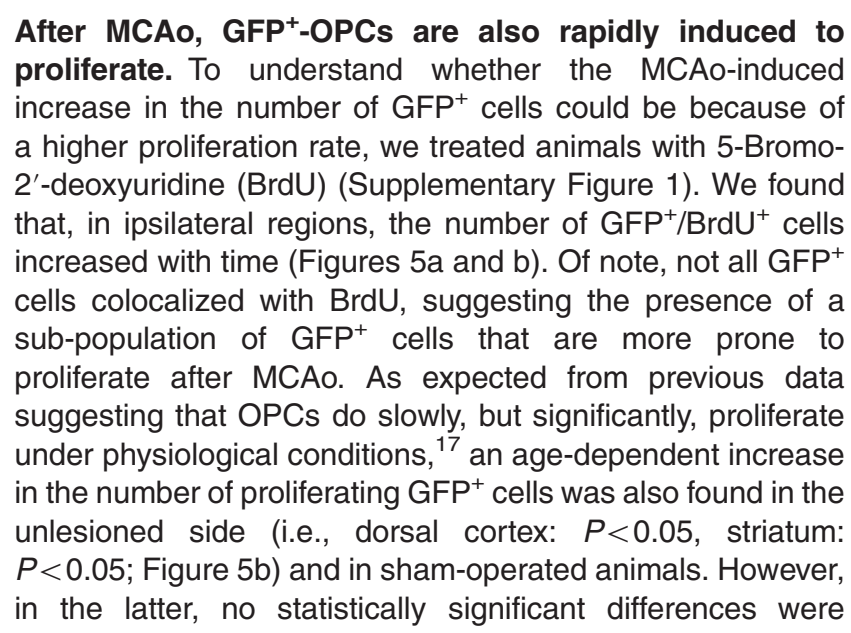

\footnotetext{
Figure 3 GFP+ cells undergo morphological changes in response to brain ischemia. (a and $\mathbf{b}$ ) Representative images of GFP immunofluorescence of contralateral (a) and ipsilateral (b) hemispheres from GPR17iCreER ${ }^{T 2}$ :CAG-eGFP mice $72 \mathrm{~h}$ after MCAo. Insets show higher magnification of representative non polarized GFP ${ }^{+}$cells with cell processes extending in all directions (contralateral side, a) or highly 'polarized' GFP' cells showing a bipolar shape, with processes aligned with the cell body and extended toward the ischemic area (ipsilateral ischemic side in $\mathbf{b}$; dotted line indicates the borders of the ischemic core). (c) Representative images of a GFP (green) and NG2 ${ }^{+}$(red) selected for the morphological analysis. Scale bar $=20 \mu \mathrm{m}$. (d) Illustration of Sholl analysis used to quantify process branching. The number of intersections made by the extending processes with each circle was automatic counted and used as a measure of process branching. (e) Illustration of skeletonized cells; Skeleton analysis was used to get information on the cell morphology complexity. (f) Representative images of GFP ${ }^{+}$cells (green) and HOECHST 33258 (blue) in contralateral and ipsilateral dorsal cortex at $72 \mathrm{~h}$, 1 week and 2 weeks after MCAo. High magnification of images at $72 \mathrm{~h}$ is reported. Scale bar $=20 \mu \mathrm{m}$. (g) Sholl analysis plot of GFP ${ }^{+}$cells and (h) bar graphs of Critical value, Critical radius and Ramification index at $72 \mathrm{~h}, 1$ week and 2 weeks after MCAo. (i) Skeleton analysis data summary. ${ }^{\star} P<0.05$; ${ }^{* \star} P<0.01$; ${ }^{* \star *} P<0.001$; Student's $t$-test
} 
a

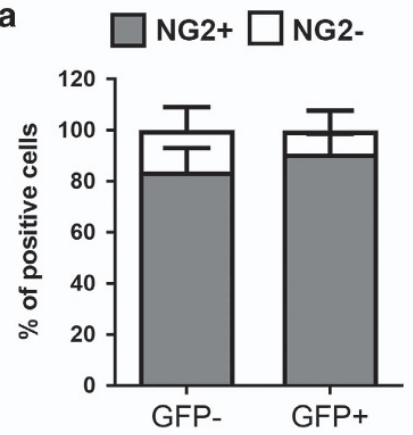

c

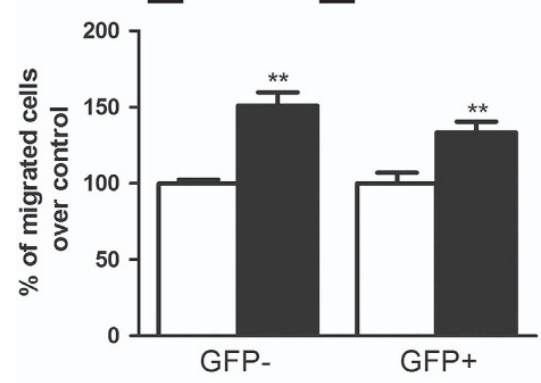

e

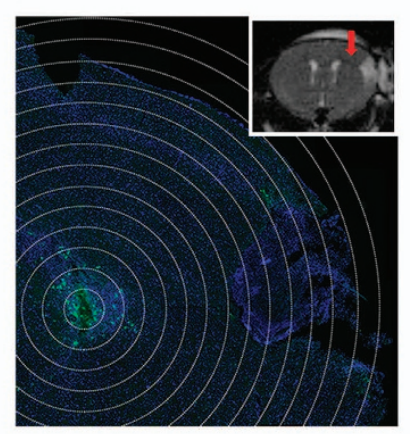

g

GFP+ GPR17-

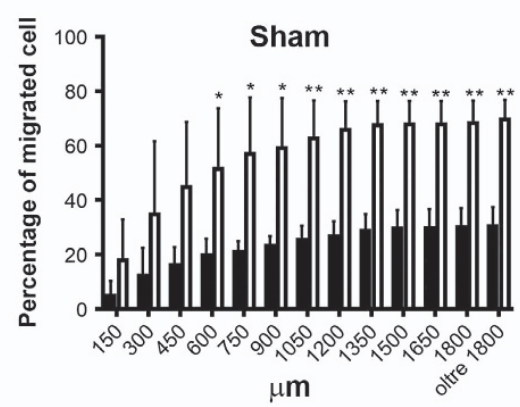

b

GPR17+

GPR17-

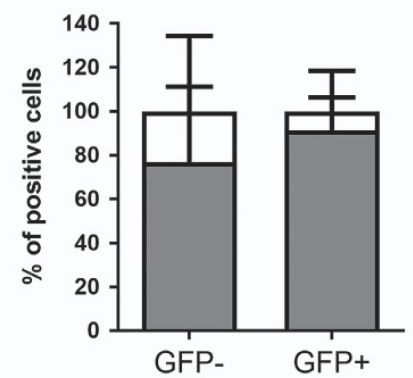

d

NG2+

NG2-

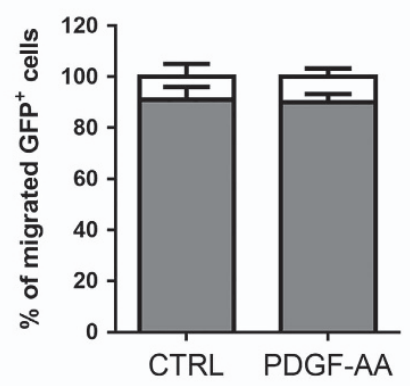

f

Sham

MCAO

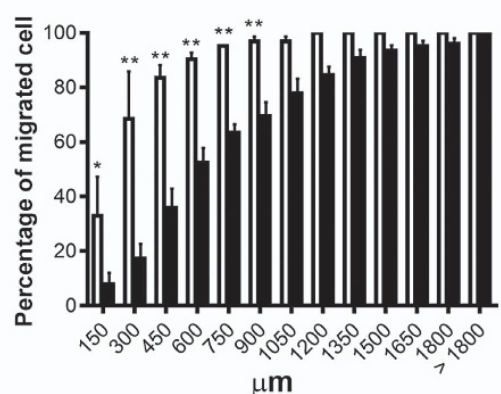

GFP+ GPR17+

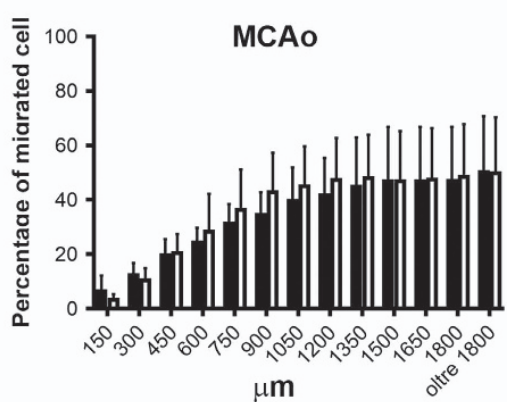

Figure 4 The migration capacity of GFP+ cells is influenced by brain ischemia. ( $\mathbf{a}$ and $\mathbf{b}$ ) Stacked bar graphs show the quantitative analysis of percentages of NG2 ${ }^{+}$and NG2 ${ }^{-}$cells (a) and of GPR17 $7^{+}$and GPR17 $7^{-}$cells (b) both within the GFP+ ${ }^{+}$and GFP ${ }^{-}$cell population ( $n=3$ coverslips from three independent OPC preparations). (c) Bar graphs show the results of the quantitative analysis of cell migration assay performed in three independent experiments of $\mathrm{GFP}^{+}$and GFP ${ }^{-}$cells. Changes in number of migrated GFP ${ }^{+}$ cells were related to control condition set to $100 \%$. ${ }^{* *} P<0.01$; Mann-Whitney analysis. (d) Stacked bar graphs show the results of the quantitative analysis of percentages of $\mathrm{NG}^{+}$and NG2 ${ }^{-}$cells within the migrated GFP+ cell population ( $n=3$ independent experiments). (e) Representative image of GFP immunohistochemistry of an ischemic wildtype mouse at 7 days after the injection. The concentric circles represent the distances from the injection site, starting from $150 \mu \mathrm{m}$. In the insert is reported the T2W image of brain coronal section of the same mouse acquired $24 \mathrm{~h}$ after MCAo and before the injection of GFP+ OPCs. The red arrow represents the injection track. (f) The bar graph shows the quantification of the percentage of GFP ${ }^{+}$cells, which have migrated at different distances from the injection site ( $n=2$ sham-operated mice; $n=3$ MCAo mice). ${ }^{*}<<0.05$; ${ }^{* \star} P<0.01$; two-way ANOVA followed by Bonferroni post-hoc analysis. (g) The bar graph shows the quantification of the percentage of GFP $/ \mathrm{GPR} 7^{+}$and $\mathrm{GFP}^{+} / \mathrm{GPR} 17^{-}$cells, which have migrated at different distances from the injection site $\left(n=2\right.$ sham-operated mice; $n=3$ MCAo mice). ${ }^{*} P<0.05$; ${ }^{*} P<0.01$; two-way ANOVA followed by Bonferroni post-hoc analysis 
detected between the ipsi- and contralateral sides at any of the analyzed time points (data not shown). Globally, these results show that, at least in part, the increased number of $\mathrm{GFP}^{+}$cells can be ascribed to ischemia-induced higher proliferation rate.

The final fate of the $\mathrm{GFP}^{+}$cells is altered by brain ischemia. To better characterize the phenotypic changes of the $\mathrm{GFP}^{+}$cells pool during the post-ischemic period, we performed a fate-mapping analysis with stage-specific oligodendrocyte markers (NG2 for early OPCs, GPR17 for immature oligodendrocytes and GSTpi for mature oligodendrocytes).

As a first step, to get more information on the early proliferating $\mathrm{GFP}^{+} / \mathrm{BrdU}^{+}$cells, we performed triple immunostainings with GFP, NG2 and BrdU antibodies (Figure 6a). At $72 \mathrm{~h}$, almost all $\mathrm{GFP}^{+} / \mathrm{BrdU}^{+}$cells still expressed NG2, indicating that during the acute reaction to injury all the proliferating recombined cells still remain at a precursor stage. Interestingly, already at 1 week, a percentage of these cells no longer expressed NG2. However, the loss of NG2 positivity reached statistical significance only at 8 weeks (i.e., $P<0.05$ in ventral cortex, corpus callosum and striatum; Figure $6 \mathrm{~b}$ ). In the contralateral side, negligible changes were observed (Figure 6b).

Our conclusion is that, after $\mathrm{MCAo}, \mathrm{GFP}^{+}$cells are initially induced to move toward the lesion while increasing their proliferation rate and that, subsequently, a subset of these cells is undergoing differentiation.

At $72 \mathrm{~h}$, the number of $\mathrm{GFP}^{+} / \mathrm{NG}^{+}$cells was increased in the ipsilateral side in a different way according to the brain region, reaching statistical significance in dorsal cortex $(P<0.05)$ (Figures $7 \mathrm{a}$ and $\mathrm{b})$. This increase was still present at 2 weeks and then disappeared (Figure $8 \mathrm{~b}$ ), indicating that, after a very early recruitment of the $\mathrm{NG}^{+} / \mathrm{GFP}^{+}$cells, a pool of this OPC sub-population is preserved and does not undergo any further changes, to likely avoid exhaustion of brain's repair abilities; conversely, a second pool of these recruited cells is addressed to maturation to sustain lesion repair.

Regarding this second pool of $\mathrm{GFP}^{+}$cells, to discriminate cells at intermediate stages from more mature phenotypes, we analyzed in detail the following cell subpopulations: $\mathrm{GFP}^{+}$/ $\mathrm{GPR}_{1} 7^{+}, \mathrm{GFP}^{+} / \mathrm{NG}^{-} / \mathrm{GSTpi}^{-}$and $\mathrm{GFP}^{+} / \mathrm{GSTpi}^{+}$cells. In line with our hypothesis, after MCAo, although less numerous compared with $\mathrm{GFP}^{+} / \mathrm{NG}^{+}$cells, $\mathrm{GFP}^{+} / \mathrm{NG}^{-}$cells initially expanded only in the ROls closer to damage $(P<0.05$ in ventral cortex at $72 \mathrm{~h}$ ); then, starting from 2 weeks, the number of $\mathrm{GFP}^{+} / \mathrm{NG}^{-} / \mathrm{GSTpi}^{-}$cells also significantly increased in corpus callosum and striatum, suggesting that ischemia is speeding up their maturation (Figures $7 \mathrm{~b}$ and $8 \mathrm{~b}$ ). Moreover, in ventral cortex and striatum, a slight increase in $\mathrm{GFP}^{+} / \mathrm{GPR} 17^{+}$ cells was observed at 8 weeks (Supplementary Figure 3). Globally, these data indicate that ischemia induces maturation of $\mathrm{GFP}^{+}$cells.

As brain injury resulting in demyelination can induce adult OPCs to reacquire some stemcellness, ${ }^{18}$ we also tested the hypothesis that the $\mathrm{GFP}^{+} / \mathrm{NG}^{-}$sub-population of cells in the MCAo brain is not actually composed of more mature precursors, but indeed represent a new ischemia-induced population of cells reverting to more immature stages. We found that, up to 8 weeks after MCAo, no $\mathrm{GFP}^{+}$cells expressed the stem cell marker GFAP (data not shown), suggesting that there is not a complete reversal to a stem cell stage. However, our data support recent results suggesting reversion to neonatal-like immature states of CNS progenitors characterized by migratory activity. ${ }^{19}$

Finally, quantitative analysis demonstrated that the number of $\mathrm{GFP}^{+} / \mathrm{GSTpi}^{+}$cells slightly increased in all the considered regions, reaching a statistically significance at 8 weeks in striatum $(P<0.05)$ (Figures $7 \mathrm{~b}$ and $8 \mathrm{a})$.

\section{Discussion}

Not only neurons but also oligodendrocytes are severely affected by brain ischemia ${ }^{20,21}$ and the loss of these cells causes myelin damage, contributing to stroke-associated deficits. Of note, the recovery of neurological function after stroke increases in parallel with white matter reorganization in rodents $^{22}$ and microstructural integrity of white matter tracts is correlated with residual motor output in stroke patients. ${ }^{23}$ Thus, understanding the long-term behavior of OPCs, the myelin-producing cells, after stroke is crucial to find new strategies to promote endogenous remyelination and functional recovery. ${ }^{24}$

In this study, we have addressed this issue by using the GPR17iCreER ${ }^{\text {T2 }}$ :CAG-eGFP mice that allows to trace the proliferation, migratory abilities, differentiation and final fate of GPR17-expressing OPCs. As GPR17 is only transiently expressed by these precursors and completely disappears before they reach terminal maturation, these mice represent the only tool to follow the destiny of cells that have expressed GPR17.

We previously showed that, in this transgenic mouse line, GPR $17^{+}$-OPCs (i.e., GFP ${ }^{+}$cells) are reluctant to differentiate under healthy conditions, but can rapidly respond to injury, suggesting they may represent a 'reserve pool' of adult progenitors maintained for repair purposes. ${ }^{10}$ Here, we provide the first comprehensive in vivo fate-mapping analysis of these cells in a model of permanent brain ischemia up to 8 weeks.

In line with our previous results, ${ }^{4,12} 72 \mathrm{~h}$ after MCAo, GPR $17^{+}$cells accumulate in the regions surrounding the lesions, and most of them still expressed the early OPC marker NG2. The increase of $\mathrm{GFP}^{+}$cells persisted for at least 8 weeks with different regional kinetics that was faster in ROls closer to the lesion. Highly relevant, a similar spatiotemporal gradient of the presence and activation of these cells has also been found in patients after traumatic brain injury. ${ }^{8}$

Our data show that the increased number of $\mathrm{GFP}^{+}$cells around the ischemic lesion is, at least in part, because of ischemia-induced proliferation. The analysis of the number of $\mathrm{GFP}^{+}$cells over time revealed that the increase of $\mathrm{GFP}^{+}$cells mainly occurred in the early phases after MCAo. At later times, the rate of increase of these cells in the ipsilateral regions became similar to that observed in the contralateral ones, indicating a reduction with time of the ischemia-mediated effect. The proliferation rate of $\mathrm{GFP}^{+}$cells indeed reached its maximum during the first week after MCAo, indicating that this pool of cells is extremely reactive to injury. Interestingly, some proliferating $\mathrm{GFP}^{+}$cells were detected in the unlesioned side, 


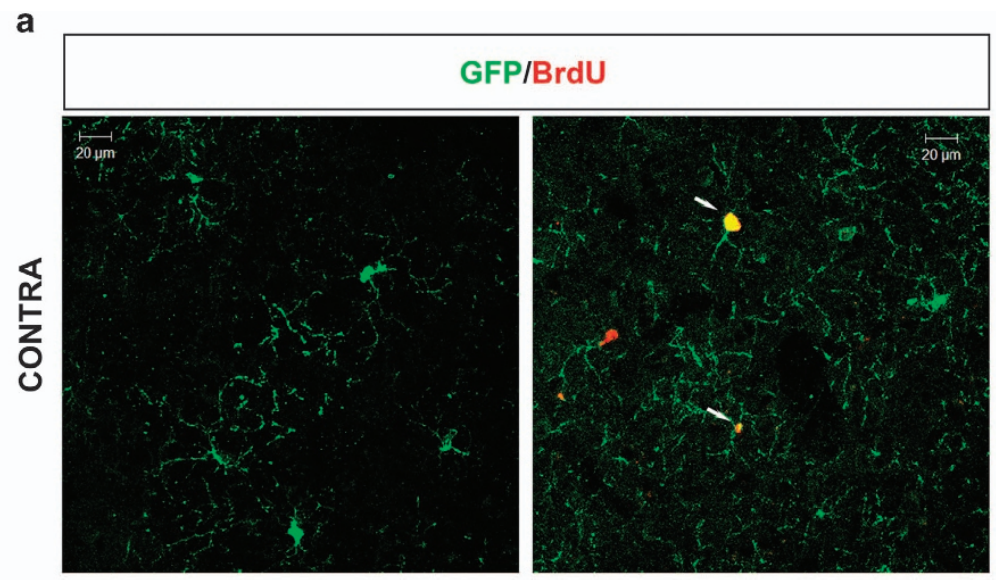

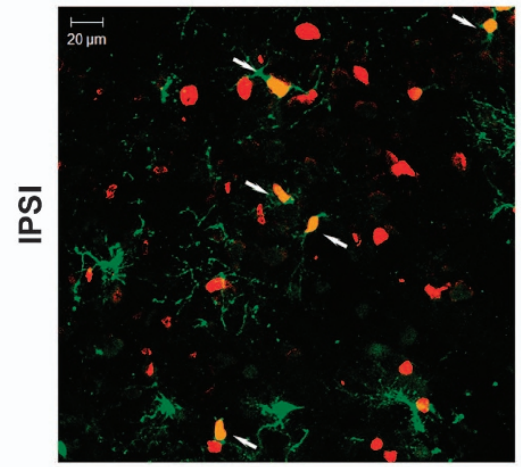

72 hours

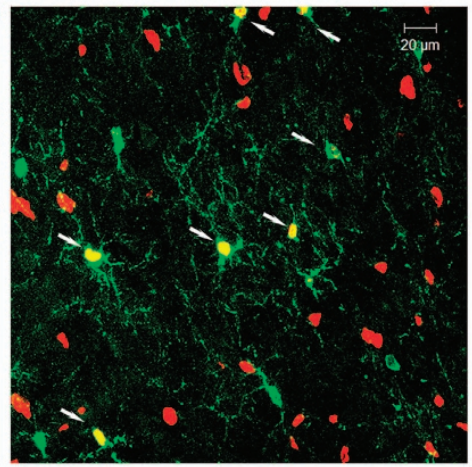

8 weeks

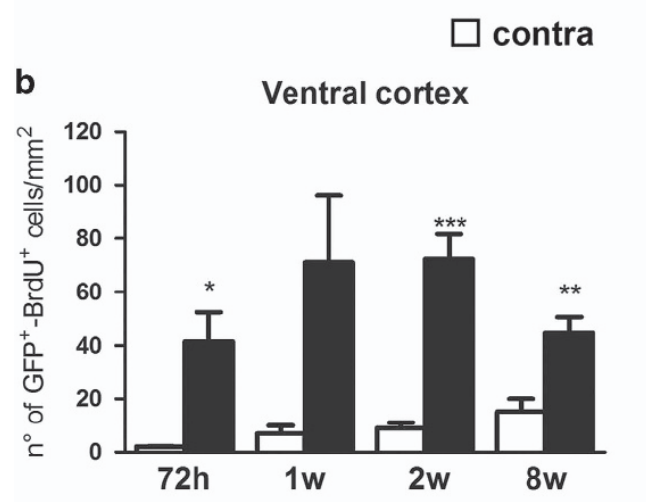

cC

ipsi
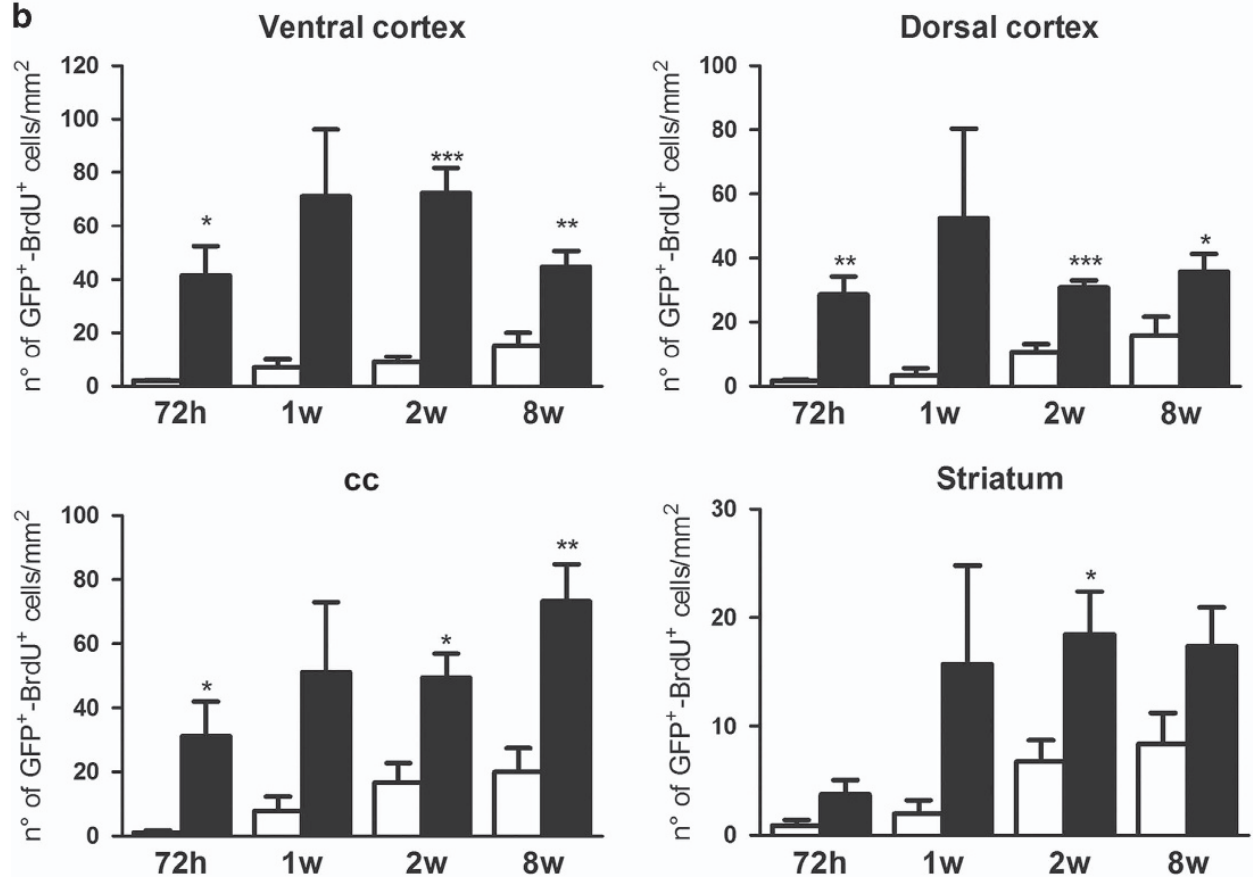

Figure 5 Brain ischemia induces proliferation of GFP ${ }^{+}$cells. (a) Representative images of GFP (green) and BrdU (red) immunofluorescence in contralateral and ipsilateral dorsal cortex of mice $72 \mathrm{~h}$ and 8 weeks after MCAo. Arrows show double-positive cells. Scale bar $=20 \mu \mathrm{m}$. (b) Bar graphs showing the quantitative analysis of the number of $\mathrm{BrdU}^{+}$-GFP ${ }^{+}$cells ( $n=3$ mice for 1 week; $n=4$ mice for $72 \mathrm{~h}$ and 2 weeks; $n=5$ mice for 8 weeks). ${ }^{*} P<0.05,{ }^{* \star} P<0.01,{ }^{* * *} P<0.001$ ipsilateral versus contralateral side; Student $t$-test. In contralateral dorsal cortex and striatum 2 weeks versus $72 \mathrm{~h}{ }^{*} P<0.05$; one-way ANOVA followed by Bonferroni post-hoc analysis 
and, consistent with previous data, ${ }^{10}$ a slower and more moderate increase of $\mathrm{GFP}^{+}$cells was observed in shamoperated mice. This confirms that under physiological conditions, OPCs slowly but steadily proliferate throughout life.

Moreover, our data indicate that, besides proliferation, the increase of $\mathrm{GFP}^{+}$cells is because of recruitment of migrating $\mathrm{GFP}^{+}$-OPCs toward the ischemic area. In this respect, GFP ${ }^{+}$OPCs underwent early morphological changes, acquiring a simpler structure that can be also interpreted as an augmented migratory capacity. Specifically, $72 \mathrm{~h}$ after MCAo, the cellular complexity of $\mathrm{GFP}^{+} / \mathrm{NG}^{+}$cells significantly decreased in the ipsilateral side, and these cells exhibited fewer and more elongated processes in the direction of the lesion. Based on previous data showing that motile OPCs lose their un-oriented radial morphology and extend processes in the direction of migration ${ }^{15}$ and through the lesion, ${ }^{25}$ we conclude that the $\mathrm{GFP}^{+} / \mathrm{NG}^{+}$cells are indeed migrating toward the lesion. This conclusion is supported by our in vitro results, and by the increased migratory abilities of $\mathrm{GFP}^{+}$cells when transplanted in MCAo mice.

These results are in line with our previous data demonstrating that GPR17 promotes OPCs migration in vitro ${ }^{16}$ and are consistent with literature results. Bipolar morphology was required for directional migration of OPCs in vitro, whereas increased number of cellular processes correlated with random and slow migration. ${ }^{26}$ In living brain slices, motile OPCs acquired a simple morphology whereas non-motile cells showed a complex morphology. ${ }^{15}$ These motile cells exhibited the same morphology described for OPCs moving from sites of proliferation to sites of injury after carotid ligation. ${ }^{27}$ As OPCs represent the majority of proliferating cells in the healthy adult brain, ${ }^{17}$ we do not rule out that some of the migrating $\mathrm{GFP}^{+} / \mathrm{NG}^{+}$cells may be newborn cells generated from the originally green-labeled GPR $17^{+}$cells.

The detected morphological changes weakened at later post-ischemia phases, when activated $\mathrm{GFP}^{+} / \mathrm{NG}^{+}$cells started maturating to myelinating phenotypes. In previous studies in healthy and stab wound injured brain, post-mitotic GPR $17^{+}$cells acquired a pre-myelinating phenotype. However, the exact relationship between proliferation and progression to mature oligodendrocytes remained uncertain, ${ }^{5,28}$ and whether and how ischemia influenced the fate of these cells was unknown. The present data clearly show that, only starting from 2 weeks and to a greater extent 8 weeks after MCAo, GFP ${ }^{+}$-proliferating cells lose NG2 positivity, suggesting lineage progression to more advanced stages and terminal differentiation.

As OPCs of the gray and white matter are known to behave in different ways, ${ }^{29}$ to evaluate whether, depending on the extracellular microenvironment, the localization of the reacting $\mathrm{GFP}^{+}$cells influences their differentiation properties, we detailed their behavior in either gray and white matter regions. Results indicate that the early recruitment of the $\mathrm{GFP}^{+} / \mathrm{NG}^{+}$ cells in the regions surrounding the lesion was exclusively related to their proximity to the ischemic area.

The role of the expanded $\mathrm{GFP}^{+} / \mathrm{NG}^{+}$cells pool in the early phases after MCAo remains unclear. These cells may proliferate to assure that a sufficient number of cells undergoes myelination, and/or to assume completely different roles implementing brain repair. In this respect, it has been hypothesized that, beyond myelination, OPCs may also have trophic functions. ${ }^{30}$ OPCs indeed express high levels of active factors and cytokines regulating crucial biological processes like proliferation, differentiation and cell survival. In hippocampal slices undergoing oxygen glucose deprivation, release of BDNF and IL-10 by co-cultured OPCs improves cell survival and proliferation. ${ }^{30}$ The trophic effect of oligodendrocytes is not only restricted to OPCs but also extends to myelin, which sustains axonal homeostasis and neuronal survival. ${ }^{31}$ Transplanted human embryonic stem cells derived OPCs decrease infiltrating inflammatory cells within the subarachnoid space ${ }^{32}$ likely through increases of CCL2, CXCL10, SICAM-1 and TIMP-1, which, may, in turn, affect the migration of inflammatory cells. ${ }^{32}$ Another possible role of the increased $\mathrm{GFP}^{+}$/ $\mathrm{NG}_{2}{ }^{-}$-pool could be to preserve the physical compartmentation of the brain. OPCs increase brain-blood barrier tightness via TGF- $\beta$ signaling ${ }^{33}$ and may be also involved in scar formation. NG2-glia, together with microglia, are the first cells to react and strongly accumulate around the injury ${ }^{34,35}$ and could be responsible for scar formation by building a high cell density area, ${ }^{36}$ as we also observed starting from 4 weeks after MCAo.

Notably, at later times after MCAo, the number of $\mathrm{GFP}^{+}$/ $\mathrm{NG}^{+}$cells in the ipsilateral is similar to that of the contralateral side, indicating that, after ischemia-induced early activation, the pool of $\mathrm{GFP}^{+} / \mathrm{NG}^{+}$cells is restored to basal levels. Similarly, after brain stab wound, the number of $\mathrm{NG}^{+}$cells progressively decreases over time, leading to restoration of their physiological density. ${ }^{10}$ Globally, these data confirm that the adult brain does have the capacity to preserve the homeostasis of the OPC pool also in case of initial loss of oligodendrocytes, as observed in cerebral hypoperfusion. ${ }^{37,38}$

Of note, the number of $\mathrm{GFP}^{+} / \mathrm{NG}^{-} / \mathrm{GST}^{-}{ }^{-}$cells, which likely are the pre-oligodendrocytes, is increased at 2 weeks after MCAo, suggesting that the initial activation of these cells is not finalized to promoting a rapid differentiation to myelinating phenotypes. In fact, the increase of percentage of GFP ${ }^{+}$ cells expressing GSTpi that reached a statistical significance only at later phases after MCAo.

In summary, this study characterizes the behavior and fate of GPR17-expressing OPCs in the ischemic brain over time. Results indicate that ischemia induces, sequentially: (i) early morphological changes of GPR $17^{+}$cells consistent with their migration toward the injury; (ii) a rapid proliferative response of $\mathrm{GFP}^{+}$cells; (iii) a later increase of recombinant cells at intermediate stages of maturation; (iv) the subsequent progression of some of these cells to myelinating phenotypes.

Of interest, GPR $17^{+}$cells undergo maturation with different kinetics in the selected ROls, depending upon their distance from the ischemic core, suggesting the existence of a gradient of factors that are released by the core area and act as differentiating agents, as nevertheless already suggested for GPR $17^{+}$-OPCs in patients after traumatic brain injury. ${ }^{8}$ Moreover, the very early activation of these cells suggests that the role of OPCs goes well beyond myelination, indicating further un-explored trophic roles. The pharmacological manipulation of GPR17 will help establishing the ability of these cells to eventually sustain myelination and to improve the functional recovery of the regions surrounding the ischemic lesion. 
Materials and Methods

Animals and experimental procedures. The procedures concerning animal care, surgery, killing were performed in accordance with national (D.L. n.26, 2014) and International laws and policies (EU Directive 2010/63/EU) and approved and authorized by the National Ministry of Health-University of Milan Committee (approval number 12/12-30012012 and 479/2015-PR). The protocol used is also in accordance with ARRIVE guidelines.

Eleven weeks old GPR17iCreER ${ }^{\top 2}$ :CAG-eGFP report mice received $10 \mathrm{mg}$ tamoxifen (Sigma-Aldrich, Taufkirchen, Germany), dissolved in 10\% ethanol and $90 \%$ corn oil, three times by gavage once every second day. After 3 weeks of wash-out a

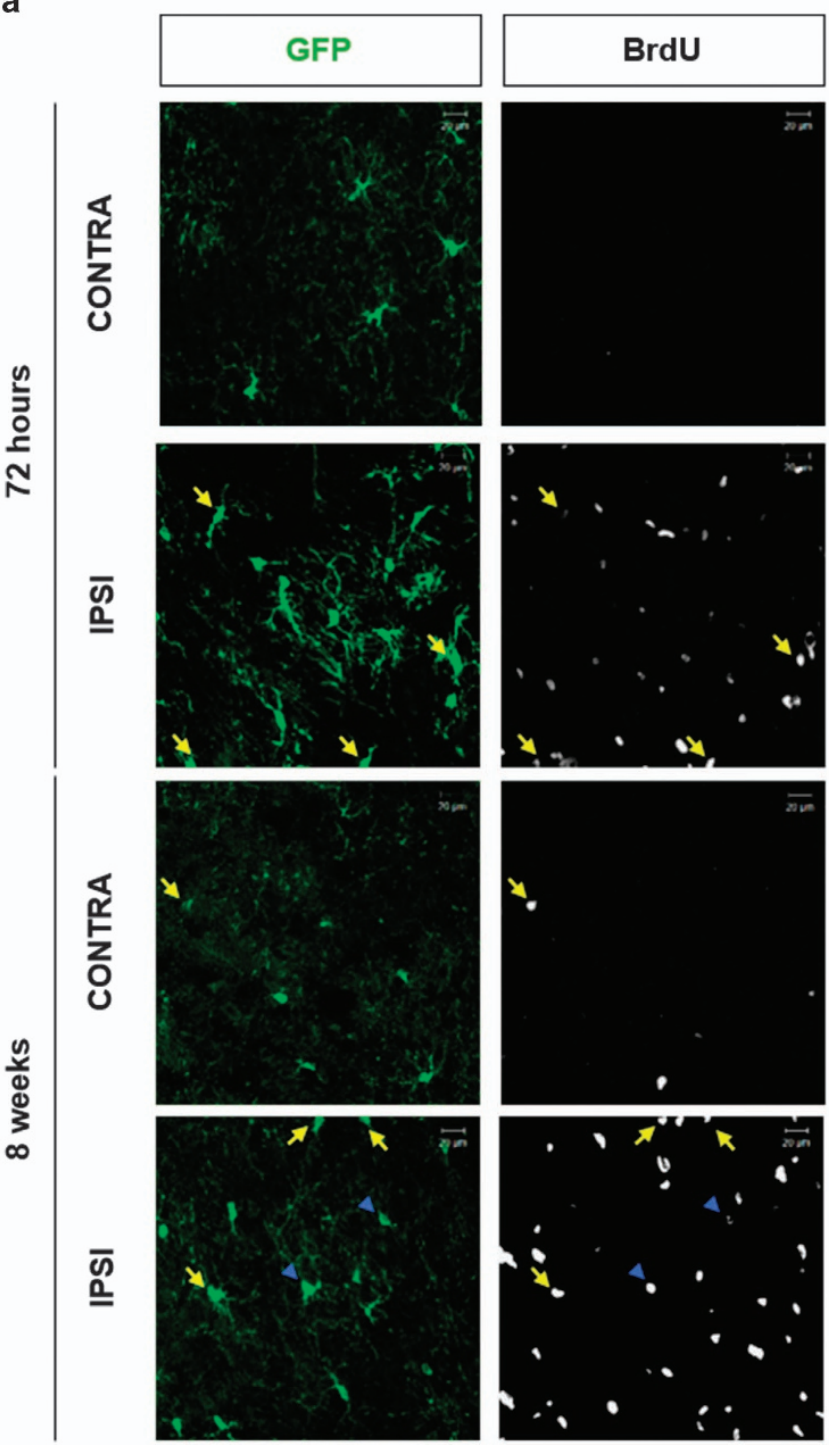

b
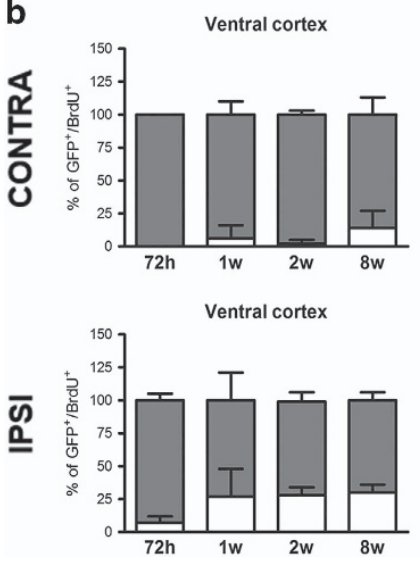

Dorsal cortex

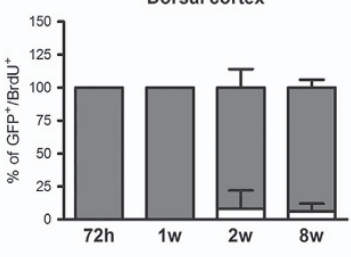

Dorsal cortex

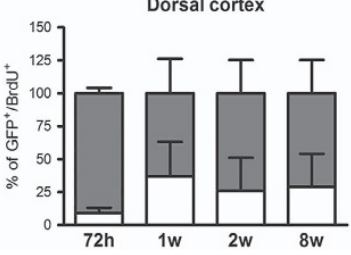

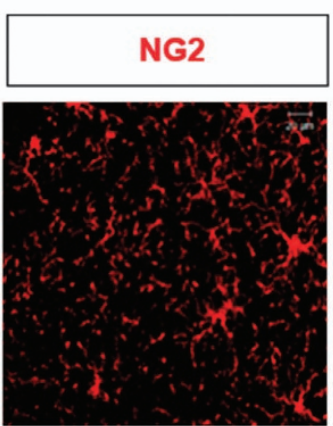
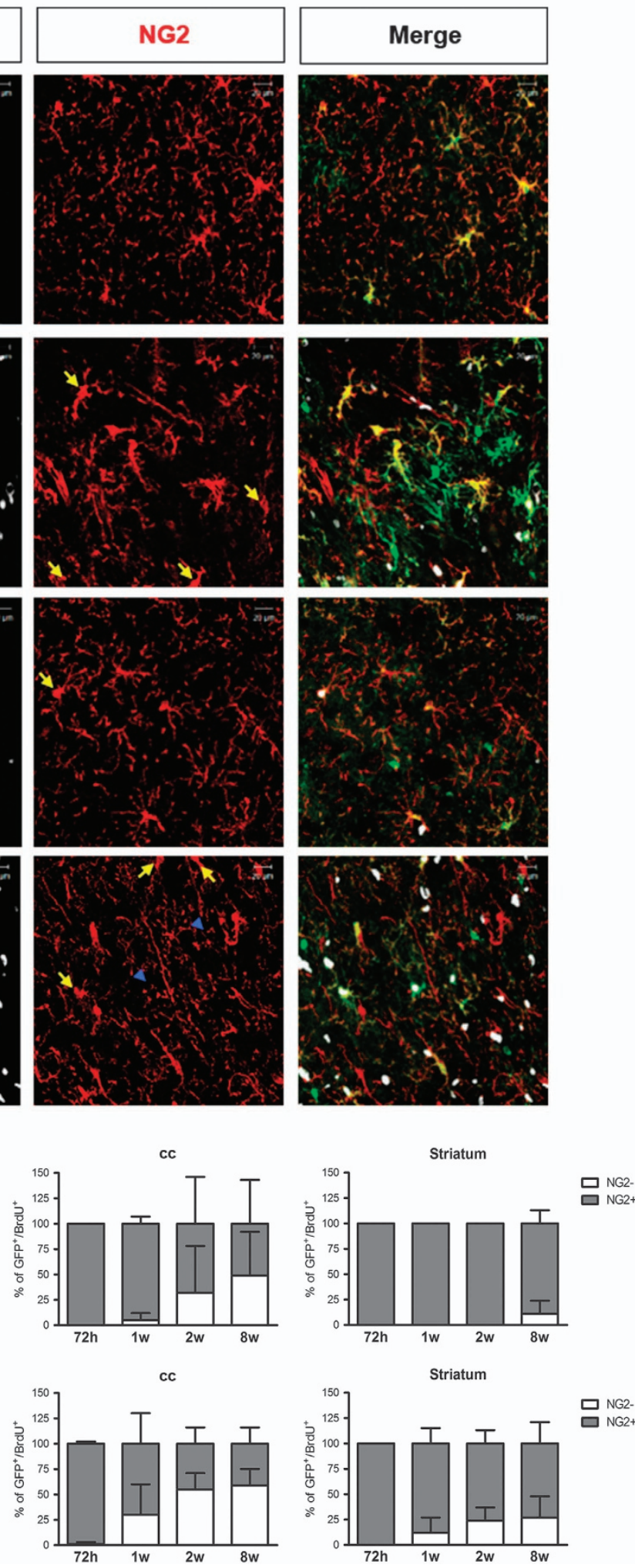
from tamoxifen, the mice were anesthetized with ketamine $(80 \mathrm{mg} / \mathrm{kg})$ and xylazine $(16 \mathrm{mg} / \mathrm{kg})$ and underwent permanent MCAo. ${ }^{39}$ Starting from 1 day before surgery, mice received $1 \mathrm{mg} / \mathrm{ml} \mathrm{BrdU}$ (Sigma-Aldrich) in drinking water supplemented with $2 \%$ sucrose for 15 days. Mice were killed at $72 \mathrm{~h}$ and $1,2,4$ and 8 weeks after MCAo ( $n=3-5$ mice for each time point) (see Supplementary Figure 1). In parallel, sham-operated mice were included in each experimental group.

Brain damage visualization. MRI investigations were performed in mice anesthetized with $1 \%$ isofluorane in $11 / \mathrm{min}$ of $\mathrm{O}_{2}$ at $72 \mathrm{~h}$ and $1,2,4$ and 8 weeks after ischemic insult using a $4.7 \mathrm{~T}$, vertical super wide bore magnet of a Bruker Avance II spectrometer with micro imaging accessory (Ettlingen, Germany). Brain damage was visualized by means of T2-weighted MR imaging using a RARE sequence. ${ }^{39}$

Immunofluorescence analysis. Mice were perfused with phosphatebuffered-saline and then $4 \%$ paraformaldehyde in phosphate-buffered-saline for at least $25 \mathrm{~min}$. Brains were removed, post-fixed $1 \mathrm{~h}$ in the same solution and cryoprotected in $30 \%$ sucrose solution until precipitation at $4{ }^{\circ} \mathrm{C}$. Coronal sections of 20- $\mu \mathrm{m}$ were incubated with the following primary antibodies: chicken anti-GFP antibody (1:1400; Aves Labs, Inc., Tigard, OR, USA), rat anti-BrdU (1:150; Abcam, Cambridge, UK), rabbit anti-GSTpi (1:500; MBL, Woburn, MA, USA), rabbit antiNG2 (1:2000; Millipore, Temecula, USA), rabbit anti-GFAP (1:300; Dako, Glostrup, Denmark) and rabbit anti-GPR17 (1:20 000; home-made antibody kind gift by $P$ Rosa). Incubation with primary antibodies was made overnight at $4{ }^{\circ} \mathrm{C}$ in PBS with $1 \%$ normal goat serum (Dako) and 0.1\% Triton-X 100, whereas for anti-NG2 in PBS with $1 \%$ normal goat serum and $0.3 \%$ Triton-X 100 . The sections were exposed for $2 \mathrm{~h}$ at room temperature to secondary antibodies (Life Technologies, Monza, Italy). For rabbit anti-NG2 and GPR17, the signal intensity was enhanced using the High Sensitivity Tyramide-Rhodaminate Signal Amplification kit (Perkin-Elmer, Monza, Italy) following the manufacturer's instructions. For triple GFP/NG2/BrdU labeling, staining of BrdU was performed last, after fixing sections with $4 \%$ paraformaldehyde for $10 \mathrm{~min}$ and incubating them with $\mathrm{HCl} 2 \mathrm{~N}$ for $45 \mathrm{~min}$ at $37^{\circ} \mathrm{C}$. Nuclei were labeled with Hoechst $33258(0.3 \mu \mathrm{g} / \mathrm{ml}$; Life Technologies). a

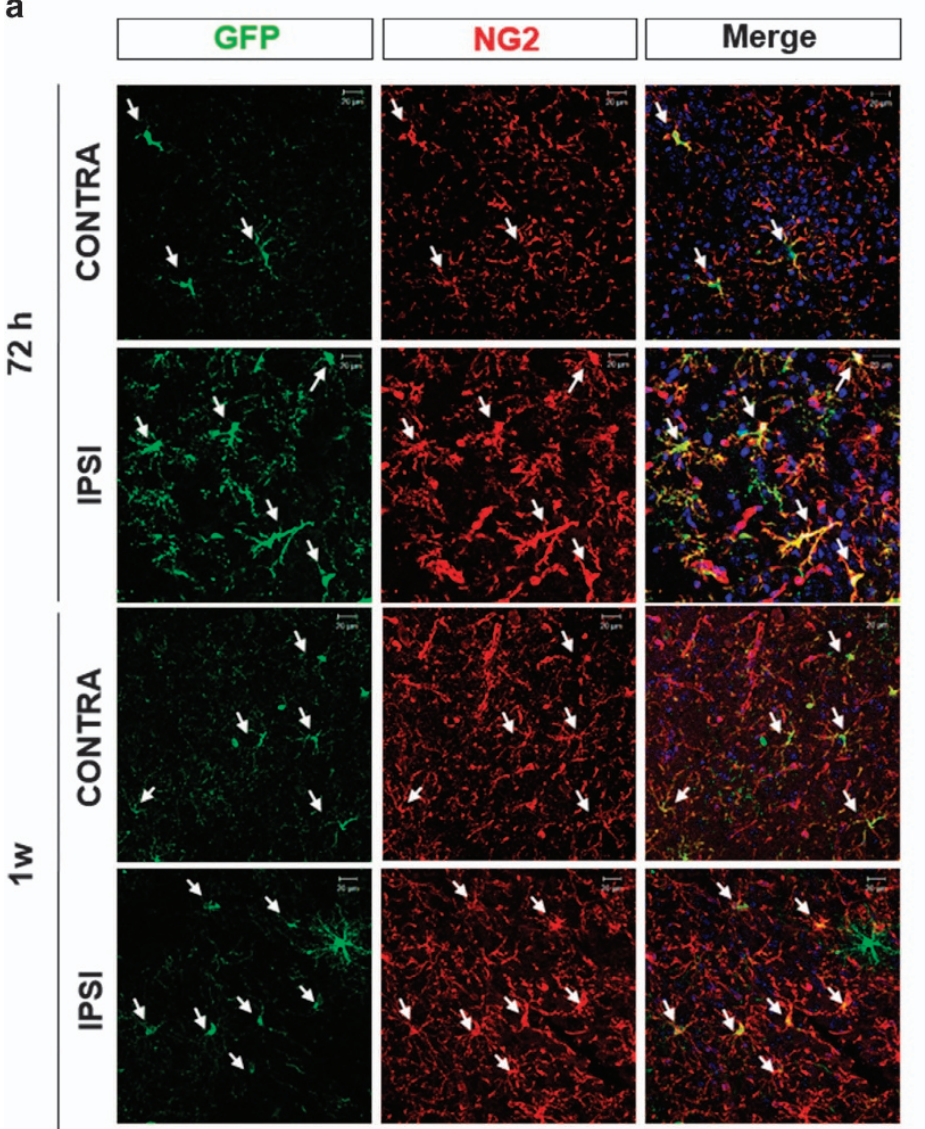

b
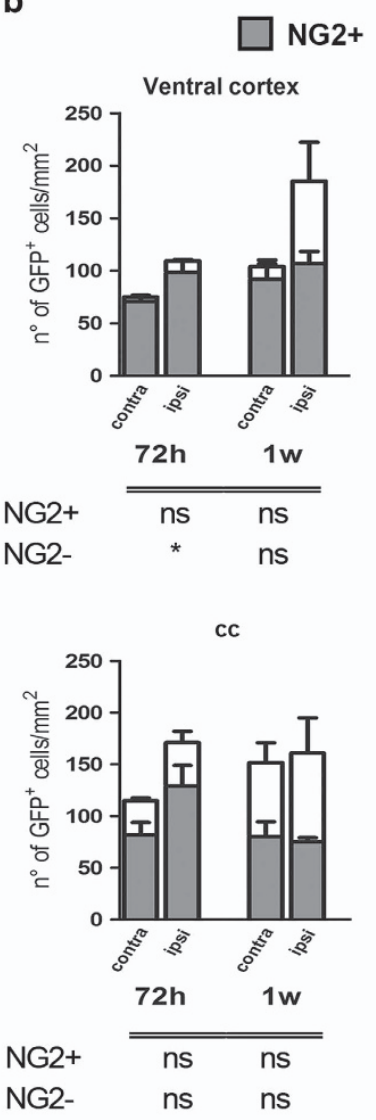

NG2-

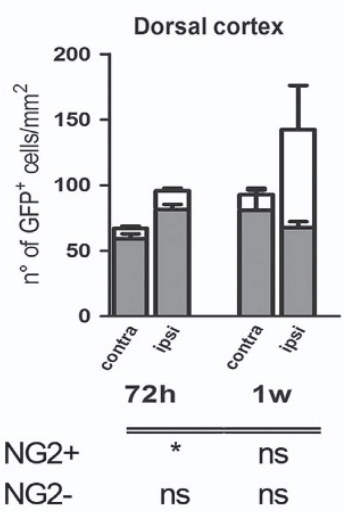

Striatum

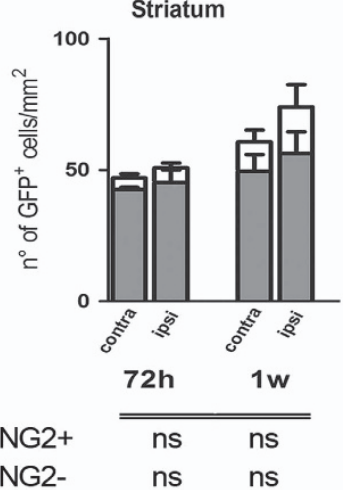

Figure 7 Early phase after MCAo, GFP cells mainly express the NG2 antigen. (a) Representative images of GFP (green) and NG2 (red) immunofluorescence in contralateral and ipsilateral dorsal cortex of mice $72 \mathrm{~h}$ and 1 weeks after MCAo. Arrows show GFP'/NG2 ${ }^{+}$cells. Scale bar $=20 \mu \mathrm{m}$. (b) Stacked bar graphs show the quantitative analysis of the number of $\mathrm{GFP}^{+} / \mathrm{NG}^{+}$cells ( $n=4$ mice $72 \mathrm{~h} ; n=3$ mice for 1 week). ${ }^{*} P<0.05$ ipsilateral versus contralateral side; Student's $t$-test

Figure 6 The fate of the GFP $/ \mathrm{BrdU}^{+}$cells is altered by brain ischemia. (a) Representative images of GFP (green), BrdU (white) and NG2 (red) immunofluorescence in contralateral and ipsilateral dorsal cortex of mice $72 \mathrm{~h}$ and 8 weeks after MCAo. Arrows (yellow) show GFP'/BrdU ${ }^{+}$cells positive for NG2 whereas head arrows (blue) show GFP ${ }^{+}$ $\mathrm{BrdU}^{+}$cells negative for NG2. Scale bar $=20 \mu \mathrm{m}$. (b) Stacked bar graphs show the quantitative analysis of percentages of $\mathrm{NG}^{+}$and NG2 ${ }^{-}$cells within the GFP ${ }^{+} / \mathrm{BrdU}^{+}$cell population in contralateral and ipsilateral ROls ( $n=3$ mice for 1 week and 8 weeks; $n=4$ mice for $72 \mathrm{~h}$ and 2 weeks) in the contralateral (upper graphs) and ipsilateral (lower graphs) side. NG2 ${ }^{+}$cells in contralateral ventral cortex: 8 w versus $72 \mathrm{~h}^{*} P<0.05$; NG2 ${ }^{+}$cells in ipsilateral ventral cortex and corpus callosum: 8 weeks versus $72 \mathrm{~h}{ }^{*} P<0.05$; NG2 ${ }^{-}$cells in ipsilateral corpus callosum and striatum: 8 weeks versus $72 \mathrm{~h}{ }^{*} P<0.05$; one-way ANOVA followed by Bonferroni post-hoc analysis. NG2 ${ }^{+}$and NG2 ${ }^{-}$cells in ipsilateral striatum: ${ }^{*} P<0.05$; one-way ANOVA 
a

a

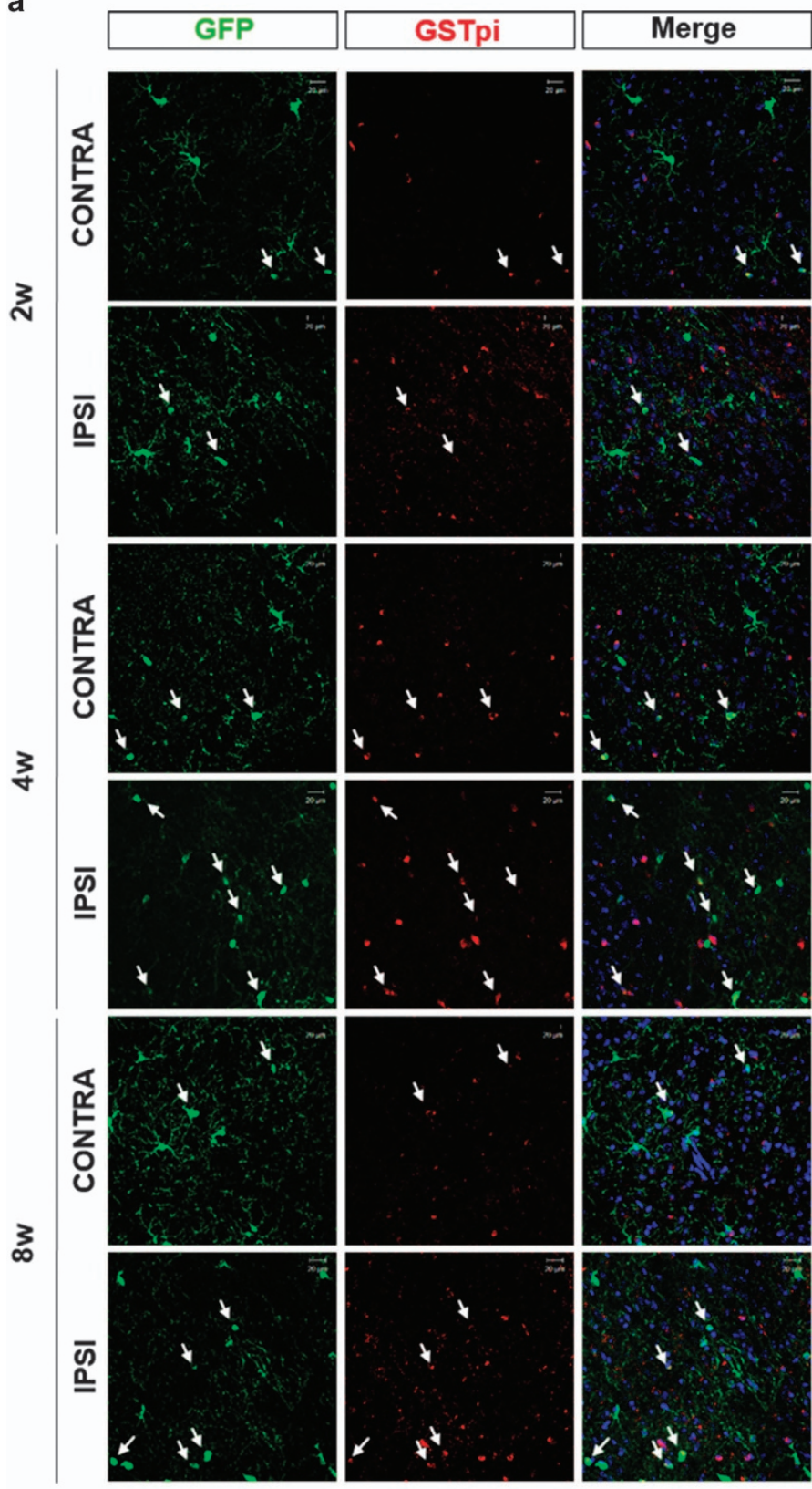

b
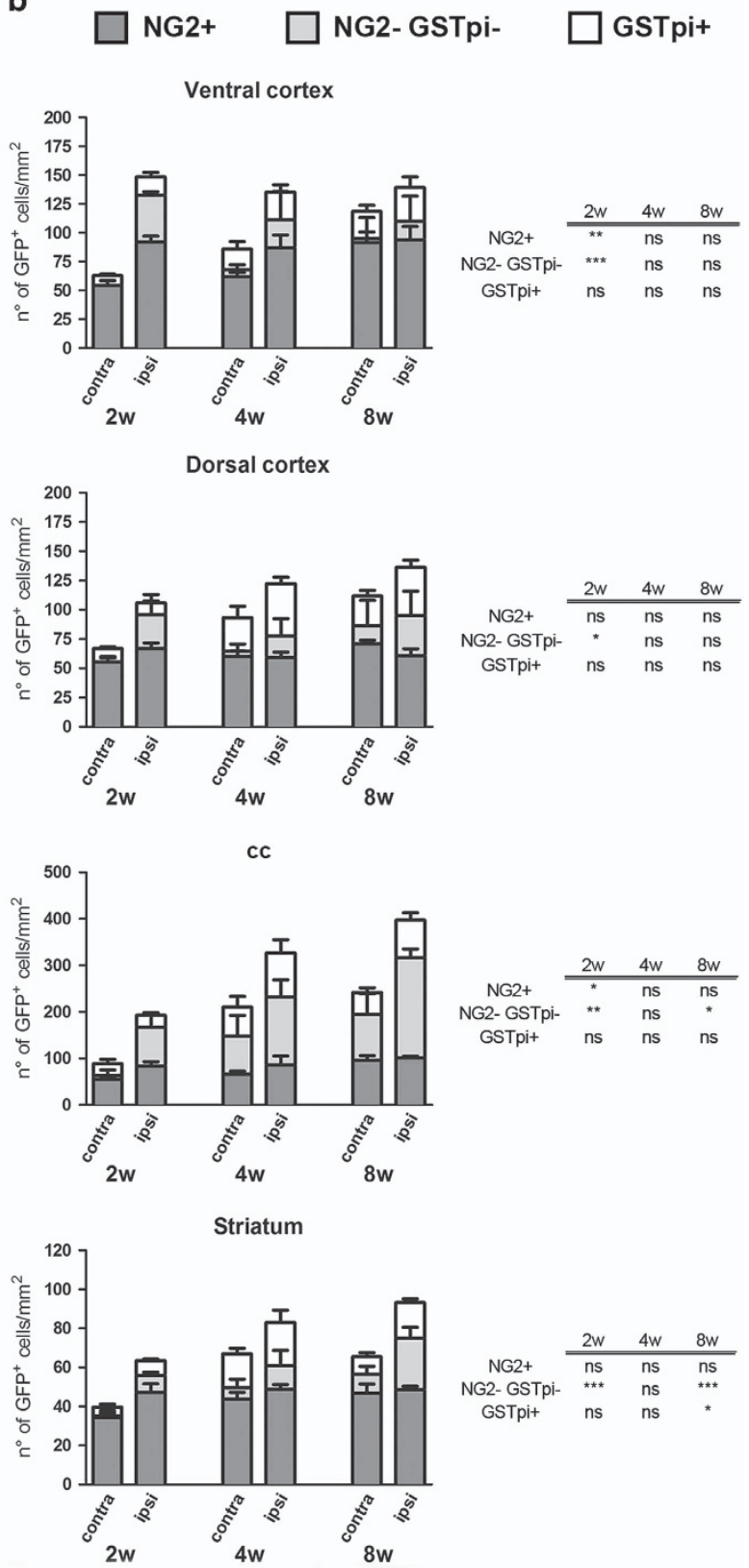

Figure 8 Late phase after MCAo, GFP ${ }^{+}$cells progressively lose the NG2 antigen and start expressing the mature oligodendrocyte marker GSTpi. (a) Representative images of GFP (green) and GSTpi (red) immunofluorescence in contralateral and ipsilateral dorsal cortex of mice 2, 4 and 8 weeks after MCAo. Arrows show GFP $/$ GSTpi $^{+}$cells. Scale bar $=20 \mu \mathrm{m}$. (b) Stacked bar graphs show the quantitative analysis of the number of $\mathrm{GFP}^{+} / \mathrm{NG}^{+}$cells, GFP ${ }^{+} / \mathrm{NG2}^{-} / \mathrm{GSTpi}^{-}$cells and GFP $+/ \mathrm{GSTpi}{ }^{+}$cells $(n=4$ mice 2 weeks; $n=3$ mice for 4 weeks; $n=5$ mice for 8 weeks). ${ }^{*} P<0.05,{ }^{* *} P<0.01,{ }^{* \star *} P<0.001$ ipsilateral versus contralateral side; Student's t-test

ROI selection and cell counts. The number of GFP-positive, doublepositive GFP/BrdU, GFP/NG2, GFP/GPR17, GFP/GSTpi and triple-positive GFP/ BrdU/NG2 was quantified, by a blinded investigator, on two slices per mouse from -1.00 to $0.00 \mathrm{~mm}$ from bregma. ${ }^{40}$ For the quantitative analysis, four anatomically defined ROls surrounding the ischemic lesion, and their respective mirror ROls in the contralateral side, were identified (ventral and dorsal cortex, corpus callosum and striatum). Briefly, after identifying the boundaries of the ischemic lesion we selected specific fields $(281.25 \times 281.25 \mu \mathrm{m})$ for cell count as illustrated in the drawing (Figure 1b). Images were acquired at $\times 40$ magnification using a confocal microscope (merge of $8-\mu \mathrm{m}$ z-stack at 2- $\mu \mathrm{m}$ intervals; LSM510 META, Zeiss, Oberkochen, Germany).
Sholl and skeleton analysis. A Sholl analysis method was developed to quantify $\mathrm{GFP}^{+}, \mathrm{GFP}^{+} / \mathrm{NG}^{+}$and $\mathrm{GFP}^{+} / \mathrm{NG}^{-}$cell morphology in immunofluorescent images of brain at $72 \mathrm{~h}, 1$ and 2 weeks after MCAo. This morphological analysis was performed only with well-identified or isolated $\mathrm{GFP}^{+}$cells, and on at least 18 cells for hemisphere of each mouse. Confocal images were acquired at each ipsilateral and contralateral dorsal cortex as detailed in drawing image (Figure 1b). The local contrast of GFP channel was enhanced and a basic grayscale morphologic erosion was performed to optimize the visualization of cellular processes. The resulting images were converted to a binary signal and analyzed using Simple Neurite Tracer plugin of the Fiji software, ImageJ(https://imagej.net/Fij/ Downloads). Cellular branches were manually traced and the center for the Sholl 
analysis was pointed at the centroid of the nucleus. Concentric circles were automatically drawn beginning at $2 \mu \mathrm{m}$ from the center and increasing $2 \mu \mathrm{m}$ with every circle.

The Sholl analysis plugin was then applied to all traced cells to collect data on the number of intersections between branches and each increasing circle to create a Sholl plot. For each mouse, a mean Sholl plot was generated. The parameters used for statistical analysis were: critical radius, critical value and ramification index.

The skeleton analysis plugin was applied in the same way and the parameters used for statistical analysis were: number of branches, number of branch endpoints and number of junctions, average and maximum branch length, and maximum primary branch length.

OPC cultures. P0-P1 mice pups were subcutaneously injected with $30 \mathrm{ng}$ tamoxifen to induce recombination and killed after 3 days. Cortices were removed, mechanically and enzymatically dissociated, suspended in Dulbecco's modified Eagle's medium containing $10 \%$ fetal bovine serum, $4 \mathrm{mM}$ L-glutamine, $1 \mathrm{mM} \mathrm{Na}$ pyruvate, $100 \mathrm{U} / \mathrm{ml}$ penicillin, $100 \mathrm{U} / \mathrm{ml}$ streptomycin (all products from EuroClone, Milano, Italy), and plated in poly-L-lysin-coated $60 \mathrm{~mm}$ dishes $\left(3 \times 10^{6}\right.$ cells). After 8 days, OPCs growing on top of a confluent monolayer of astrocytes were manually detached. Contaminating microglial cells were eliminated by plating detached cells on culture dishes for $1 \mathrm{~h}$. OPCs were, then, collected and plated onto poly-DL-ornithinecoated dishes (Sigma-Aldrich) in Neurobasal medium (Life Technologies) containing $2 \%$ B27, $4 \mathrm{mM}$ L-glutamine, $100 \mathrm{U} / \mathrm{ml}$ penicillin, $100 \mathrm{U} / \mathrm{ml}$ streptomycin, $10 \mathrm{ng} / \mathrm{ml}$ platelet derived growth factor (PDGF-AA; Sigma-Aldrich) and $10 \mathrm{ng} / \mathrm{ml}$ basic fibroblast growth factor (bFGF; Space Import Export, Milan, Italy) to promote cell proliferation. After 2-3 days, cells were detached with accutase (Millipore) and used for migration assay or directly injected in wild-type mouse brain. Immunocytochemistry for GPR17 and NG2 was done to characterize the isolated OPCs. ${ }^{3}$

Cell migration assay. Migration of $\mathrm{GFP}^{+}-\mathrm{OPCs}$ was performed with Boyden chambers ( $8 \mu \mathrm{m}$ pore size filter; Constar, Corning, NY, USA) as previously described. ${ }^{16}$ Briefly, the chamber was nested inside the well of 24-well plates and $5 \times 10^{4}$ OPCs were seeded in the top of each insert with $200 \mu$ of neurobasal medium. The bottom well was filled with $600 \mu \mathrm{l}$ of medium containing the chemoattractant PDGF-AA $(50 \mathrm{ng} / \mathrm{ml})$. After $17 \mathrm{~h}$, non-migrated cells were removed from the top compartment with a cotton swab, whereas cells that had migrated to the lower side of the filter were fixed with $4 \%$ paraformaldehyde and stained with Hoechst 33258, anti-GFP and anti-NG2 antibodies (see above). Images were acquired at $\times 20$ magnification under an inverted fluorescence microscope (200M; Zeiss, Oberkochen, Germany) and cells counted using the Image $\mathrm{J}$ software (US National Institutes of Health, Bethesda, Marylan, USA). Data are expressed as a percentage of basal migration, that is, the migration of OPCs without chemoattractant.

OPCs in vivo transplantation in MCAo mice. Wild-type mice (C57B//6J, 2- to 3-month old) underwent MCAo as described above. As a control, shamoperated mice were used. For cell transplantation, we followed a protocol previously described. ${ }^{29}$ One day after MCAo, $1 \mu \mathrm{l}$ of cell suspension (90000 OPCs, see above) was injected in the ipsilateral striatum using a Hamilton syringe (Hamilton, 75 SN $5 \mu$ l, Bonaduz, Switzerland). Coordinates of the site of injection were chosen based on the lesion area visualized by MRI (approximately $+0.2 \mathrm{~mm}$ anterioposterior, $-2.0 \mathrm{~mm}$ medio-lateral, $-3.0 \mathrm{~mm}$ dorso-ventral relative to the bregma). Mice were killed 1 week post-transplantation and the brains collected as described above. For each brain, we quantified the number of $\mathrm{GFP}^{+}, \mathrm{GFP}^{+}-\mathrm{GPR} 17^{+}$and GFP'-GPR17 ${ }^{-}$cells, which migrated from the injection site up to $>1800 \mu \mathrm{m}$ in the surrounding tissue, and then calculated the percentage of moving cells. Cells remaining in the needle injection groove were not counted. We analyzed at least three slides for each mice and 2-3 animals per condition.

Statistical analysis. The effect of time and ischemia on the number of GFP cells was evaluated by two-way ANOVA analysis followed by Bonferroni post-hoc analysis. The effect of time on proliferated $\mathrm{GFP}^{+}$cells was evaluated by one-way ANOVA analysis followed by Bonferroni post-hoc analysis. The significance of the between-group differences was computed by means of unpaired Student's $t$-test (ipsilateral versus contralateral side). Two-way ANOVA and Mann-Whitney analysis were used to detect statistical significance in migration assay. Pearson correlation test was used to evaluate the correlation between the number of $\mathrm{GFP}^{+}$cells and the days from the surgery. Simple linear regression analysis was used to test whether the slopes and intercepts of the equation of a straight line obtained for contralateral and ipsilateral side were significantly different for each ROI. Data are expressed as mean \pm S.E.

\section{Conflict of Interest}

The authors declare no conflict of interest.

Acknowledgements. This work was supported by: ERA-NET 'Network of European Funding for Neuroscience Research' (NEURON) project 'RENEW IT' to MPA and ET.; Fondazione Cariplo Milano, grant number: 2012-0546 to LS and grant number: 2015-0910 to MF; Italian Society of Pharmacology (SIF) - MSD fellowship and Fondazione Umberto Veronesi (FUV) fellowship to EB. The authors thank Raffaella lacubino, Elisa Chiodo and Alessia Montini for excellent technical assistance.

1. El Waly B, Macchi M, Cayre M, Durbec P. Oligodendrogenesis in the normal and pathological central nervous system. Front Neurosci 2014; 8: 145.

2. Nishiyama A, Komitova M, Suzuki R, Zhu X. Polydendrocytes (NG2 cells): multifunctional cells with lineage plasticity. Nat Rev Neurosci 2009; 10: 9-22.

3. Fumagalli M, Daniele S, Lecca D, Lee PR, Parravicini C, Fields RD et al. Phenotypic changes, signaling pathway, and functional correlates of GPR17-expressing neural precursor cells during oligodendrocyte differentiation. J Biol Chem 2011; 286: 10593-10604.

4. Lecca D, Abbracchio MP. Deorphanisation of G protein-coupled receptors: a tool to provide new insights in nervous system pathophysiology and new targets for psycho-active drugs. Neurochem Int 2008; 52: 339-351.

5. Boda E, Vigano F, Rosa P, Fumagalli M, Labat-Gest V, Tempia F et al. The GPR17 receptor in NG2 expressing cells: focus on in vivo cell maturation and participation in acute trauma and chronic damage. Glia 2011; 59: 1958-1973.

6. Chen Y, Wu H, Wang S, Koito H, Li J, Ye F et al. The oligodendrocyte-specific G proteincoupled receptor GPR17 is a cell-intrinsic timer of myelination. Nat Neurosci 2009; 12 . 1398-1406.

7. Fumagalli M, Bonfanti E, Daniele S, Zappelli E, Lecca D, Martini $C$ et al. The ubiquitin ligase Mdm2 controls oligodendrocyte maturation by intertwining mTOR with $\mathrm{G}$ protein-coupled receptor kinase 2 in the regulation of GPR17 receptor desensitization. Glia 2015; 63 : 2327-2339.

8. Franke $\mathrm{H}$, Parravicini $\mathrm{C}$, Lecca D, Zanier ER, Heine $\mathrm{C}$, Bremicker $\mathrm{K}$ et al. Changes of the GPR17 receptor, a new target for neurorepair, in neurons and glial cells in patients with traumatic brain injury. Purinergic Signal 2013; 9: 451-462.

9. Ceruti S, Villa G, Genovese T, Mazzon E, Longhi R, Rosa P et al. The P2Y-like receptor GPR17 as a sensor of damage and a new potential target in spinal cord injury. Brain 2009; 132(Pt 8): 2206-2218.

10. Vigano F, Schneider S, Cimino M, Bonfanti E, Gelosa P, Sironi L et al. GPR17 expressing NG2-Glia: oligodendrocyte progenitors serving as a reserve pool after injury. Glia 2016; 64 287-299.

11. Mao FX, Li WJ, Chen HJ, Qian LH, Buzby JS. White matter and SVZ serve as endogenous sources of glial progenitor cells for self-repair in neonatal rats with ischemic PVL. Brain Res 2013; 1535: 38-51.

12. Ciana $P$, Fumagalli $M$, Trincavelli ML, Verderio $C$, Rosa $P$, Lecca $D$ et al. The orphan receptor GPR17 identified as a new dual uracil nucleotides/cysteinyl-leukotrienes receptor. EMBO J 2006; 25: 4615-4627.

13. Lecca D, Trincavelli ML, Gelosa $P$, Sironi L, Ciana $P$, Fumagalli $M$ et al. The recently identified P2Y-like receptor GPR17 is a sensor of brain damage and a new target for brain repair. PLOS ONE 2008; 3: e3579.

14. Tanaka K, Nogawa S, Suzuki S, Dembo T, Kosakai A. Upregulation of oligodendrocyte progenitor cells associated with restoration of mature oligodendrocytes and myelination in peri-infarct area in the rat brain. Brain Res 2003; 989: 172-179.

15. Schmidt C, Ohlemeyer C, Labrakakis C, Walter T, Kettenmann H, Schnitzer J. Analysis of motile oligodendrocyte precursor cells in vitro and in brain slices. Glia 1997; 20: 284-298.

16. Coppi E, Maraula G, Fumagalli M, Failli P, Cellai L, Bonfanti E et al. UDP-glucose enhances outward $\mathrm{K}(+)$ currents necessary for cell differentiation and stimulates cell migration by activating the GPR17 receptor in oligodendrocyte precursors. Glia 2013; 61: 1155-1171.

17. Dawson MR, Polito A, Levine JM, Reynolds R. NG2-expressing glial progenitor cells: an abundant and widespread population of cycling cells in the adult rat CNS. Mol Cell NeurosCi 2003; 24: 476-488

18. Kondo T, Raff M. Oligodendrocyte precursor cells reprogrammed to become multipotential CNS stem cells. Science 2000; 289: 1754-1757.

19. Moyon S, Dubessy AL, Aigrot MS, Trotter M, Huang JK, Dauphinot L et al. Demyelination causes adult CNS progenitors to revert to an immature state and express immune cues that support their migration. J Neurosci 2015; 35: 4-20.

20. Arai K, Lo EH. Oligovascular signaling in white matter stroke. Biol Pharm Bull 2009; 32 1639-1644.

21. Dewar D, Underhill SM, Goldberg MP. Oligodendrocytes and ischemic brain injury. J Cereb Blood Flow Metab 2003; 23: 263-274. 
22. Li L, Jiang $Q$, Ding $G$, Zhang $L$, Zhang ZG, Li $Q$ et al. MRI identification of white matter reorganization enhanced by erythropoietin treatment in a rat model of focal ischemia. Stroke 2009; 40: 936-941.

23. Schulz R, Braass H, Liuzzi G, Hoerniss V, Lechner P, Gerloff C et al. White matter integrity of premotor-motor connections is associated with motor output in chronic stroke patients. Neuroimage Clin 2015; 7: 82-86.

24. Shi H, Hu X, Leak RK, Shi Y, An C, Suenaga J et al. Demyelination as a rational therapeutic target for ischemic or traumatic brain injury. Exp Neurol 2015; 272: 17-25.

25. Hughes EG, Kang SH, Fukaya M, Bergles DE. Oligodendrocyte progenitors balance growth with self-repulsion to achieve homeostasis in the adult brain. Nat Neurosci 2013; 16 : 668-676.

26. Biname F, Sakry D, Dimou L, Jolivel V, Trotter J. NG2 regulates directional migration of oligodendrocyte precursor cells via Rho GTPases and polarity complex proteins. J Neurosci 2013; 33: 10858-10874.

27. Falahati S, Breu M, Waickman AT, Phillips AW, Arauz EJ, Snyder S et al. Ischemia-induced neuroinflammation is associated with disrupted development of oligodendrocyte progenitors in a model of periventricular leukomalacia. Dev Neurosci 2013; 35: 182-196.

28. Boda E, Di Maria S, Rosa P, Taylor V, Abbracchio MP, Buffo A. Early phenotypic asymmetry of sister oligodendrocyte progenitor cells after mitosis and its modulation by aging and extrinsic factors. Glia 2015; 63: 271-286.

29. Vigano F, Mobius W, Gotz M, Dimou L. Transplantation reveals regional differences in oligodendrocyte differentiation in the adult brain. Nat Neurosci 2013; 16: 1370-1372.

30. Miyamoto N, Pham LD, Seo JH, Kim KW, Lo EH, Arai K. Crosstalk between cerebra endothelium and oligodendrocyte. Cell Mol Life Sci 2014; 71: 1055-1066.

31. Nave KA. Myelination and support of axonal integrity by glia. Nature 2010; 468: 244-252.

32. Kim H, Walczak P, Kerr C, Galpoththawela C, Gilad AA, Muja N et al. Immunomodulation by transplanted human embryonic stem cell-derived oligodendroglial progenitors in experimental autoimmune encephalomyelitis. Stem Cells 2012; 30: 2820-2829.

33. Seo JH, Maki T, Maeda M, Miyamoto N, Liang AC, Hayakawa K et al. Oligodendrocyte precursor cells support blood-brain barrier integrity via TGF-beta signaling. PLOS ONE 2014; 9: $\mathrm{e} 103174$.

34. Matsumoto H, Kumon $\mathrm{Y}$, Watanabe $\mathrm{H}$, Ohnishi T, Shudou M, Chuai M et al. Accumulation of macrophage-like cells expressing NG2 proteoglycan and lba1 in ischemic core of rat brain after transient middle cerebral artery occlusion. J Cereb Blood Flow Metab 2008; 28 : 149-163.

35. Levine JM. Increased expression of the NG2 chondroitin-sulfate proteoglycan after brain injury. J Neurosci 1994; 14: 4716-4730.

36. Dimou L, Gallo V. NG2-glia and their functions in the central nervous system. Glia 2015; 63: 1429-1451.

37. Mclver SR, Muccigrosso M, Gonzales ER, Lee JM, Roberts MS, Sands MS et al. Oligodendrocyte degeneration and recovery after focal cerebral ischemia. Neuroscience 2010; 169: 1364-1375.

38. McQueen J, Reimer MM, Holland PR, Manso Y, McLaughlin M, Fowler JH et al. Restoration of oligodendrocyte pools in a mouse model of chronic cerebral hypoperfusion. PLOS ONE 2014; 9 : e87227.

39. Gelosa P, Lecca D, Fumagalli M, Wypych D, Pignieri A, Cimino M et al. Microglia is a key player in the reduction of stroke damage promoted by the new antithrombotic agent ticagrelor. J Cereb Blood Flow Metab 2014; 34: 979-988

40. Franklin K, Paxinos G. The Mouse Brain in Stereotaxic Coordinates. Academic Press: San Diego, CA, USA, ISBN Number 0-12-26607-6; Library of Congress: QL937F72 1997. published by Nature Publishing Group. This work is licensed under a Creative Commons Attribution 4.0 International License. The images or other third party material in this article are included in the article's Creative Commons license, unless indicated otherwise in the credit line; if the material is not included under the Creative Commons license, users will need to obtain permission from the license holder to reproduce the material. To view a copy of this license, visit http://creativecommons.org/licenses/by/4.0/

(C) The Author(s) 2017

Supplementary Information accompanies this paper on Cell Death and Disease website (http://www.nature.com/cddis) 